\title{
$\alpha 7$ Nicotinic Acetylcholine Receptors Occur at Postsynaptic Densities of AMPA Receptor-Positive and -Negative Excitatory Synapses in Rat Sensory Cortex
}

\author{
Robert B. Levy and Chiye Aoki \\ New York University Center for Neural Science, New York, New York 10003
}

NMDA receptor (NMDAR) activation requires concurrent membrane depolarization, and glutamatergic synapses lacking AMPA receptors (AMPARs) are often considered "silent" in the absence of another source of membrane depolarization. During the second postnatal week, NMDA currents can be enhanced in rat auditory cortex through activation of the $\alpha 7$ nicotinic acetylcholine receptor $(\alpha 7 \mathrm{nAChR})$. Electrophysiological results support a mainly presynaptic role for $\alpha 7 \mathrm{nAChR}$ at these synapses. However, immunocytochemical evidence that $\alpha 7 \mathrm{nAChR}$ is prevalent at postsynaptic sites of glutamatergic synapses in hippocampus and neocortex, along with emerging electrophysiological evidence for postsynaptic nicotinic currents in neocortex and hippocampus, has prompted speculation that $\alpha 7 n A C h R$ allows for activation of NMDAR postsynaptically at synapses lacking AMPAR. Here we used dual immunolabeling and electron microscopy to examine the distribution of $\alpha 7 n A C h R$ relative to AMPAR (GluR1, GluR2, and GluR3 subunits combined) at excitatory synapses in somatosensory cortex of adult and 1-week-old rats. $\alpha 7 \mathrm{nAChR}$ occurred discretely over most of the thick postsynaptic densities in all cortical layers of both age groups. AMPAR immunoreactivity was also detectable at most synapses; its distribution was independent of that of $\alpha 7 \mathrm{nAChR}$. In both age groups, approximately onequarter of asymmetrical synapses were $\alpha 7 \mathrm{nAChR}$ positive and AMPAR negative. The variability of postsynaptic $\alpha 7 \mathrm{nAChR}$ labeling density was greater at postnatal day (PD) 7 than in adulthood, and PD 7 neuropil contained a subset of small AMPA receptor-negative synapses with a high density of $\alpha 7 n A C h R$ immunoreactivity. These observations support the idea that acetylcholine receptors can aid in activating glutamatergic synapses and work together with AMPA receptors to mediate postsynaptic excitation throughout life.

Key words: sensory cortex; receptive field properties; $\alpha 7$ nicotinic acetylcholine receptor; glutamate; AMPA receptor; NMDA receptor; synaptic plasticity; early postnatal development; postsynaptic density; immunocytochemistry; electron microscopy
Plasticity of receptive field properties in sensory cortex depends on experience-dependent modification of glutamatergic pathways (Kleinschmidt et al., 1987; Fox et al., 1996; Rasmusson, 2000) and cholinergic modulation of these pathways (Bear and Singer, 1986; Sillito and Murphy, 1987; Müller and Singer, 1989; Baskerville et al., 1997; Kilgard and Merzenich, 1998). Although developmental studies have focused on muscarinic acetylcholine receptors, recent knowledge regarding central nicotinic receptors, particularly the $\alpha 7$ nicotinic acetylcholine receptor subunit ( $\alpha 7 \mathrm{nAChR})$, indicates that these too are important for synaptic plasticity. Specifically, $\alpha 7 \mathrm{nAChR}$ subunits (1) form homo-oligomeric channels with greater $\mathrm{Ca}^{2+}$ permeability than NMDA receptor (NMDAR) (McGehee, 1999), (2) are prevalent during the first postnatal week, before onset of the critical period for experiencedependent developmental plasticity (Fuchs, 1989; Bina et al., 1995; Broide et al., 1995), and (3) enhance NMDA currents

\footnotetext{
Received Dec. 12, 2001; revised March 13, 2002; accepted March 22, 2002.

This research was supported by National Institutes of Health (NIH) Grants R01 NS41091 and R01 NEI 13145-01 to C.A., and NIH P30 EY13079 core grant, National Institute of Mental Health Training Grant 5T32MH195424-10, and Office of Naval Research Solicitation No. 99-019 to the Center for Neural Science. We thank Claudia Farb, Mona Lubin, and Veeravan Mahadomrongkul for discussion and technical assistance.

The work described in this paper was presented at the Society for Neuroscience 31st annual meeting, San Diego, CA, November 10-15, 2001 (abstract 362.15).

Correspondence should be addressed to Chiye Aoki, New York University Center for Neural Science, 4 Washington Place, Room 809, New York, NY 10003. E-mail: chiye@cns.nyu.edu.

Copyright (ㄷ) 2002 Society for Neuroscience $\quad 0270-6474 / 02 / 225001-15 \$ 15.00 / 0$
}

specifically at synapses of neonatal cortex lacking AMPA receptor (AMPAR) activity (Aramakis and Metherate, 1998; Aramakis et al., 2000).

Despite its prevalence, the role of $\alpha 7 \mathrm{nAChR}$ in modulating excitatory transmission and long-term synaptic changes is unclear. Much of the physiological effect of nicotine apparently results from presynaptic modulation of glutamatergic pathways, i.e., enhanced glutamate release (McGehee et al., 1995; Role and Berg, 1996; Jones et al., 1999). However, electrophysiological evidence exists for direct activation of postsynaptic nAChR in hippocampus (Alkondon et al., 1998; Frazier et al., 1998a,b; Hefft et al., 1999) and neocortex (Roerig et al., 1997; Chu et al., 2000). Also, previous immunocytochemical results showed a primarily somatodendritic distribution of $\alpha 7 \mathrm{nAChR}$ within neocortical and hippocampal pyramidal neurons (Dominguez del Toro et al., 1994).

Past EM immunocytochemical work by us and others agrees with these immunocytochemical findings: $\alpha 7 \mathrm{nAChR}$ is concentrated at postsynaptic sites of asymmetric synapses in cortex (Lubin et al., 1999) and hippocampus (Fabian-Fine et al., 2001). These synapses are presumably excitatory (Gray, 1959; Altschuler et al., 1984; Somogyi et al., 1986; Aoki et al., 1991). Although this suggests that some of the direct or indirect effects of nicotine occur via postsynaptic glutamate receptors, morphology alone cannot reveal the glutamate receptor subtypes at these $\alpha 7 \mathrm{nAChR}$-immunopositive synapses. Immunocytochemical studies of hippocampus indicate that NMDARs are present in most asymmetric synapses throughout postnatal development, whereas 
AMPARs are acquired selectively (Nusser et al., 1998; Kharazia and Weinberg, 1999; Liao et al., 1999; Petralia et al., 1999; Shi et al., 1999). These results complement physiological evidence from hippocampus (Isaac et al., 1995; Liao et al., 1995; Durand et al., 1996) and neocortex (Wu et al., 1996; Isaac et al., 1997; Rumpel et al., 1998) that many NMDAR-containing synapses lack AMPAR function early in development. These synapses are often considered physiologically "silent" without the local depolarization required for NMDAR activity (Feldman et al., 1999). Might $\alpha 7 \mathrm{nAChR}$ contribute to postsynaptic activation of these synapses? To address this question, we examined the distribution of $\alpha 7 \mathrm{nAChR}$ relative to AMPARs at asymmetric synapses in neonatal and adult rat somatosensory cortex. EM immunocytochemistry was used to resolve the presynaptic versus postsynaptic location of $\alpha 7 \mathrm{nAChR}$ and to determine whether the presence of $\alpha 7 \mathrm{nAChR}$ at nascent synapses precedes the arrival of AMPARs.

\section{MATERIALS AND METHODS}

Tissue preparation. Adult (200-300 gm) and postnatal day (PD) 7 Sprague Dawley rats were deeply anesthetized with sodium pentobarbital $(50 \mathrm{mg} / \mathrm{kg}$ body weight) and then perfused transcardially with a mixture of $1 \%$ glutaraldehyde and $4 \%$ paraformaldehyde in $0.1 \mathrm{~m}$ phosphate buffer (PB), pH 7.4. Brains were postfixed by immersion at room temperature (RT) for $1 \mathrm{hr}$ (for adults) or overnight (for PD 7) in the same fixative. The prolonged postfixation for neonatal brains was included to compensate for less complete perfusion attributable to their relatively undeveloped vasculature. Variations in the extent of fixation did not have a measurable effect on subsequent quantitative immunolabeling results within each age group. Coronal sections, $40 \mu \mathrm{m}$ thick for adults, $60-80$ $\mu \mathrm{m}$ for PD 7, were made with a vibrating microtome (Leica Microsystems), and fixation was terminated by treatment with $1 \%$ sodium borohydride in $0.1 \mathrm{M}$ PB. Sections were stored in PBS, pH 7.4 containing $0.02 \%$ sodium azide at $4^{\circ} \mathrm{C}$ for up to 2 months before use in experiments, except for representative sections that were mounted on gelatin-coated glass slides and Nissl stained according to standard histological methods.

Pre-embedding immunocytochemistry for AMPA receptor. Pre-embedding immunocytochemistry using horseradish peroxidase (HRP)-diaminobenzidine (DAB) for visualization was chosen to ensure the most sensitive detection of AMPAR subunits. Coronal sections containing somatosensory (S1) cortex (Paxinos and Watson, 1998) were subjected to 6-10 rapid freeze-thaw cycles using $20 \%$ DMSO as a cryoprotectant to enhance antibody penetration (Wouterlood and Jorritsma-Byham, 1993). Sections were rinsed several times in PBS, incubated for $1 \mathrm{hr}$ at RT in $1 \%$ bovine serum albumin (BSA)/PBS to block unspecific binding sites, and then incubated for $1-2 \mathrm{~d}$ at $\mathrm{RT}$ in a mixture of AMPAR subunit antibodies [rabbit $\alpha$ GluR1, 1:450, and rabbit $\alpha$ GluR2/3, 1:320; both purchased from Chemicon (Temecula, CA)] diluted in $1 \%$ BSA/PBS. Sections were rinsed three times with PBS, incubated for $1 \mathrm{hr}$ at RT in biotinylated anti-rabbit IgG (Vector Laboratories, Burlingame, CA), and then rinsed again three times with PBS. Immunoreactivity was visualized using HRP-DAB (ABC Elite kit, Vector Laboratories). Sections were then processed immediately for electron microscopy (see below), apart from one set that was mounted on glass slides and used for light microscopy.

Tissue processing for electron microscopy. After AMPAR immunocytochemistry, sections were immersed for $1 \mathrm{hr}$ at RT with $1 \% \mathrm{OsO}_{4}$ in 0.1 M PB. Although many EM studies using postembedding immunocytochemistry have used osmium-free processing to preserve optimal immunoreactivity, these methods do not allow detection of HRP-DAB reaction product, and they also yield poorer ultrastructural preservation than is obtained with processing using osmium. In our laboratory, osmium treatment was compatible with optimal subsequent detection of $\alpha 7 \mathrm{nAChR}$ by postembedding immunocytochemistry (see the following section). After osmium treatment, sections were dehydrated in stepwise concentrations of ethanol up to $70 \%$ and immersed for $1-3 \mathrm{~d}$ at $4^{\circ} \mathrm{C}$ in $4 \%$ uranyl acetate in $70 \%$ ethanol. Sections were then dehydrated and embedded in EMBED 812 between Aclar sheets (Electron Microscopy Sciences, Fort Washington, PA). Sections were then drawn under a microscope equipped with a drawing tube, taking note of prominent features (e.g., large blood vessels, pial surface, areal density of pyramidal neurons, and border of the corpus callosum) for use in later identification of cortical layers under the electron microscope. Portions of each section spanning all layers of S1 cortex were capsule embedded, and 70-90 nm sections were cut on an MT-7 ultramicrotome (RMC, Tucson, AZ) and collected on Formvar-coated grids. Grids were then subjected to postembedding $\alpha 7 \mathrm{nAChR}$ labeling (see below) or viewed directly using a JEOL 1200 XL electron microscope (JEOL Inc., Tokyo, Japan).

Postembedding immunocytochemistry for $\alpha 7 n A C h R$. $\alpha 7 \mathrm{nAChR}$ labeling was performed by the postembedding gold (PEG) procedure of Erisir et al. (1997) modified from that of Phend et al. (1992). Conditions were adjusted to gain optimal detection of $\alpha 7 \mathrm{nAChR}$ by PEG while maintaining high-quality ultrastructural preservation (particularly of membranes) and preservation of HRP-DAB reaction product corresponding to AMPAR subunit immunoreactivity. Mouse monoclonal antibody 306, directed against a predicted cytoplasmic domain of $\alpha 7 \mathrm{nAChR}$ (Schoepfer et al., 1990; McLane et al., 1992), was obtained from Research Biochemicals International (Natick, MA) and used at a dilution of 1:250. This antibody was used previously in a light microscopic study of $\alpha 7 \mathrm{nAChR}$ distribution in adult rat brain (Dominguez del Toro et al., 1994) and more recently in an EM study of adult rat hippocampus CA1 (Fabian-Fine et al., 2001). In the latter instance, the specificity of synaptic labeling with monoclonal antibody (mAb) 306 was confirmed by the use of a polyclonal antibody directed against a region containing the same epitope; mitochondrial labeling seen with mAb 306 was shown to be a lower-specificity reaction with a species of $48 \mathrm{kDa}$, smaller than the native molecular mass of the $\alpha 7 \mathrm{nAChR}$ subunit. Incubation time in primary antibody was $2.5 \mathrm{hr}$; the inclusion of $0.1 \%$ Triton X-100 in the incubation mixture to remove osmium and enhance antibody penetration allowed us to avoid etching steps that cause severe deterioration of ultrastructure (Phend et al., 1992). Longer incubation times (up to $18 \mathrm{hr}$ ) were avoided, because this did not improve the extent or specificity of $\alpha 7 \mathrm{nAChR}$ labeling and caused detectable loss of HRP-DAB reaction product. Gold-conjugated anti-mouse secondary antibody $(10 \mathrm{~nm})$ was obtained from Ted Pella, Inc. (Redding, CA) and used at 1:40 dilution. Samples in which primary antibody was omitted showed virtually no labeling. After PEG, grids were postfixed for $10 \mathrm{~min}$ in $2 \%$ glutaraldehyde and counterstained for $20-30 \mathrm{sec}$ with Reynold's lead citrate to produce acceptable levels of contrast in the section without reducing the detection of HRP-DAB reaction product. Grids were then air dried and viewed under the electron microscope.

Quantitative analysis. In samples from each age group, cortical layers were identified under the electron microscope by comparing prominent features with drawings of the flat embedded tissue (see Tissue processing for electron microscopy above) and by comparison with Nissl-stained sections. In each region, neuropil was sampled only near the tissue-resin interface where penetration of pre-embedding immunoreagents was thorough, as assessed by the overall extent of HRP-DAB labeling. Random fields were photographed at $20,000 \times$ magnification, excluding those in which cell bodies, blood vessels, or empty space occupied more than half the field. Approximately $365 \mu \mathrm{m}^{2}$ of neuropil was analyzed in each cortical layer in each animal.

Micrographs were printed at a final magnification of 50,000×. Asymmetric synapses were identified, and postsynaptic elements were classified as dendritic spines or dendritic shafts, by established morphological criteria (Peters et al., 1991). Both axospinous and axon-shaft synapses were included in the analysis; most of the identifiable synapses were axospinous (see Results). A fraction of the postsynaptic profiles were not clearly identifiable as spine or shaft, particularly in the neonatal group; these profiles were included in the analysis as long as they did not clearly belong to another category (e.g., axosomatic or axoaxonal synapses). Symmetric synapses were less numerous and rarely immunolabeled. Therefore these were excluded from the quantitative analysis.

Synapses were assessed for AMPAR and $\alpha 7 \mathrm{nAChR}$ labeling on the basis of examination of the photographs printed for comparable density and contrast; for details of the criteria used to assign degrees of labeling in particular figures, see the figure legends. Postsynaptic labeling for AMPARs was assessed by the local presence of electron-dense floccular HRP-DAB product directly over the postsynaptic density (PSD). When present, HRP-DAB product was uniformly distributed over the PSD.

Assessment of labeling by $10 \mathrm{~nm}$ gold particles representing $\alpha 7 \mathrm{nAChR}$ staining took into account the distance between the gold particle and the antigen binding site; i.e., particles falling on the PSD were considered part of the postsynaptic membrane, whereas those on the synaptic cleft were assumed to belong to either the presynaptic or postsynaptic membrane with equal probability (except for data presented in Fig. $2 A$, where labeling over the cleft was categorized separately). Active zone length 

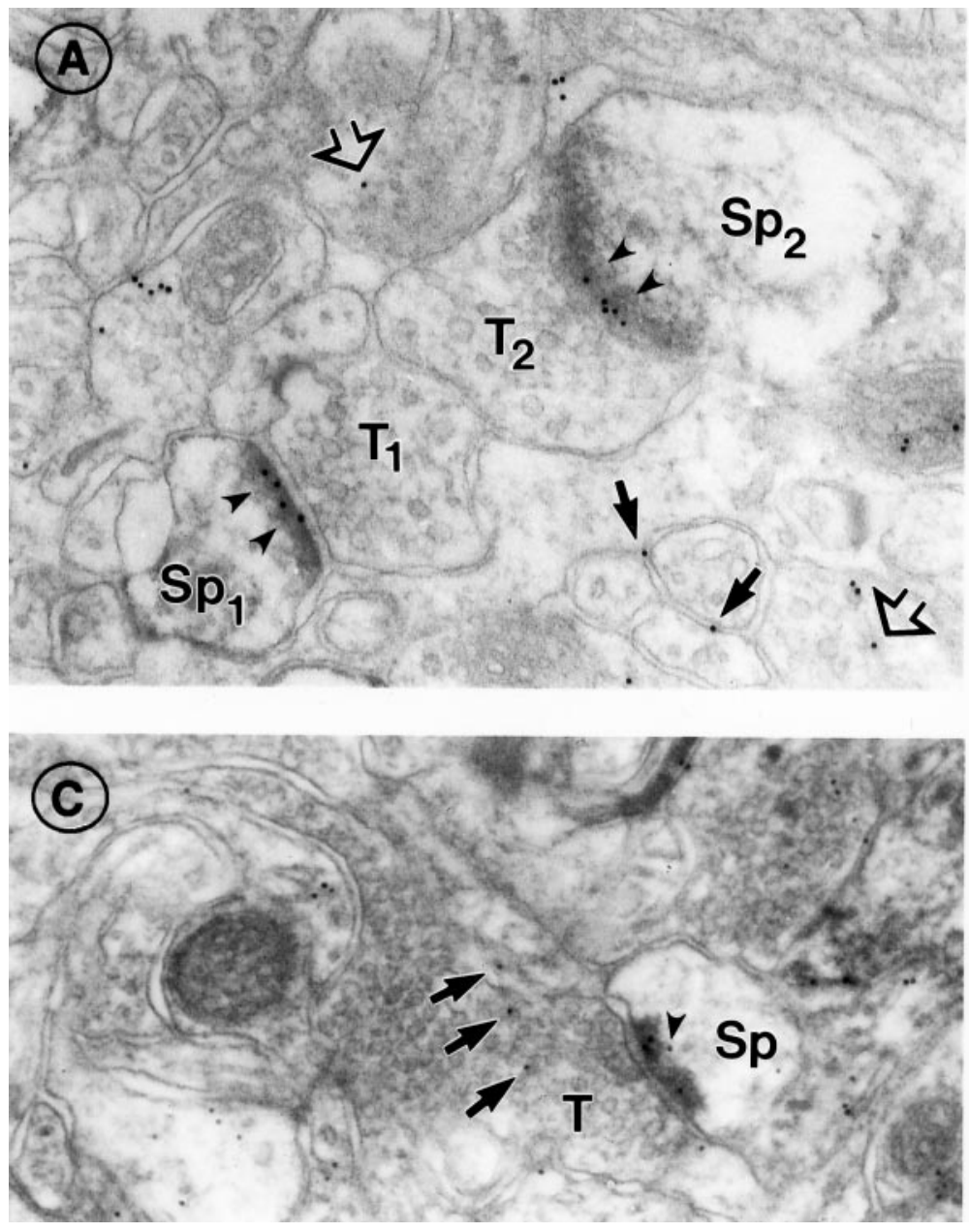

Figure 1. $\alpha 7 \mathrm{nAChR}$ immunoreactivity at asymmetric synapses of adult somatosensory cortex. $A$, Electron micrograph showing two axon terminals ( $T_{1}$, $\left.T_{2}\right)$ forming synapses with dendritic spines $\left(S p_{1}, S p_{2}\right)$ in layers II/III. $\alpha 7 \mathrm{nAChR}$ labeling $(10 \mathrm{~nm}$ gold particles, indicated by arrowheads) is seen over the PSD in both synapses. $\alpha 7 \mathrm{nAChR}$ is also seen near plasma membranes (black arrows) and in the cytoplasm (open arrows) of adjacent neuronal processes. $B$, The PSD of a synapse formed by an axon terminal $\left(T_{1}\right)$ onto a spine $(S p)$ in layers II/III, viewed en face, shows gold particles (arrowheads) distributed at random across its surface. An adjacent synapse $\left(T_{2}\right)$ onto a dendritic shaft $(S h)$ is strongly labeled with HRP-DAB reaction product indicating the presence of AMPAR (curved arrow; see more examples in Fig. 5). C, An axon terminal ( $T)$ forming a synapse with a spine (Sp) in layer VI, showing $\alpha 7 \mathrm{nAChR}$ labeling on (no symbol) and near (arrowhead) the PSD, as well as vesicle-associated labeling (arrows) in the presynaptic terminal. $D, \alpha 7 \mathrm{nAChR}$ labeling of rough endoplasmic reticulum (ER) in a pyramidal cell body of layers II/III. On ER cisternae cut in section, gold particles are located preferentially on the cytoplasmic side of the ER membrane (arrowheads; compare with Fig. $2 F$ ). Asterisks denote the ER lumen. Scale bar (shown in $D$ for $A-D): 200 \mathrm{~nm}$.

was determined using a measuring pen (Precision Technology Devices, Skokie, IL) calibrated to the scale bar imprinted on each micrograph. To simplify analysis, perforated synapses (those with discontinuous active zones) were excluded. Variations between data sets were tested for statistical significance by ANOVA followed by unpaired two-tailed $t$ tests (Microsoft EXCEL software); specific details are provided in Results and figure legends.

\section{RESULTS}

\section{Subcellular distribution of $\alpha 7 \mathrm{nAChR}$ in adult cortex}

In adult cortex, $10 \mathrm{~nm}$ gold particles corresponding to $\alpha 7 \mathrm{nAChR}$ immunoreactivity were concentrated over thick PSDs of asymmetric (typically axospinous) synapses throughout superficial, middle, and deep cortical layers (Fig. $1 A, S p_{1}, S p_{2}, B, C$ ). In cases where PSDs were separated across two active zones or perforated within a single active zone, gold particles clustered specifically over PSDs and were almost absent along nonjunctional synaptic plasma membranes (data not shown). Thick PSDs with high and low densities of immunogold occurred immediately adjacent to one another (Fig. 1B). More than two-thirds of all asymmetric postsynaptic profiles were immmunoreactive for $\alpha 7 \mathrm{nAChR}$, and this value did not vary significantly across layers or between animals (Table 1, Adult, Total). Asymmetric synapses also showed labeling at the presynaptic membrane and in the adjacent cytoplasm (Fig. 1B,C).

Labeling was distributed more sparsely over nonsynaptic portions of plasma membranes of dendritic spines and within the cytoplasm of dendritic spines (Fig. 1C, arrowhead) and shafts (data not shown). In contrast, a subcellular compartment other than the PSD that showed a high density of $\alpha 7 \mathrm{nAChR}$ was the rough endoplasmic reticulum (Fig. $1 D$ ), which was highly immunoreactive in both pyramidal and nonpyramidal cells. The predominance of immunogold labeling over PSDs, as indicated by these examples, was confirmed by quantitative analysis of the distribution pattern of colloidal gold particles within the vicinity of 420 synapses sampled across varying laminar depths of adult 


\begin{tabular}{|c|c|c|c|c|c|c|c|c|}
\hline & \multicolumn{4}{|l|}{ Adult } & \multicolumn{4}{|l|}{ PD 7} \\
\hline & AMPAR +/- & AMPAR + & AMPAR ++ & Total & AMPAR +/- & AMPAR + & AMPAR ++ & Total \\
\hline \multicolumn{9}{|c|}{ Superficial } \\
\hline$\alpha 7(-)$ & $11.8 \pm 3.7$ & $11.7 \pm 1.7$ & $4.8 \pm 3.8$ & $28.3 \pm 7.0$ & $18.4 \pm 6.8$ & $15.0 \pm 7.4$ & $1.0 \pm 0.9$ & $34.5 \pm 7.3$ \\
\hline$\alpha 7(+)$ & $19.9 \pm 3.2$ & $41.3 \pm 25.8$ & $10.5 \pm 8.6$ & $71.7 \pm 7.0$ & $20.7 \pm 8.1$ & $38.2 \pm 8.0$ & $6.7 \pm 6.0$ & $65.5 \pm 7.3$ \\
\hline Total & $31.7 \pm 6.4$ & $53.0 \pm 14.3$ & $15.3 \pm 11.7$ & $(n=257)$ & $39.1 \pm 14.7$ & $53.2 \pm 8.8$ & $7.7 \pm 6.9$ & $(n=181)$ \\
\hline \multicolumn{9}{|l|}{ Middle } \\
\hline$\alpha 7(-)$ & $6.9 \pm 2.5$ & $13.4 \pm 5.3$ & $2.0 \pm 1.7$ & $22.3 \pm 6.2$ & $11.7 \pm 6.1$ & $10.3 \pm 1.6$ & $(0)$ & $22.0 \pm 6.9$ \\
\hline$\alpha 7(+)$ & $18.1 \pm 6.1$ & $51.3 \pm 2.9$ & $8.2 \pm 3.3$ & $77.7 \pm 6.2$ & $31.2 \pm 4.1$ & $44.0 \pm 3.5$ & $2.9 \pm 2.6$ & $78.0 \pm 6.9$ \\
\hline Total & $25.1 \pm 5.6$ & $64.7 \pm 2.7$ & $10.2 \pm 3.2$ & $(n=286)$ & $42.8 \pm 2.0$ & $54.3 \pm 3.9$ & $2.9 \pm 2.6$ & $(n=129)$ \\
\hline \multicolumn{9}{|l|}{ Deep } \\
\hline$\alpha 7(-)$ & $15.2 \pm 5.2$ & $14.1 \pm 0.4$ & $1.7 \pm 1.8$ & $31.0 \pm 6.7$ & $7.0 \pm 1.0$ & $15.6 \pm 7.6$ & $0.8 \pm 1.3$ & $23.3 \pm 8.4$ \\
\hline$\alpha 7(+)$ & $32.8 \pm 6.7$ & $30.8 \pm 9.7$ & $5.4 \pm 2.7$ & $69.0 \pm 6.7$ & $27.2 \pm 3.2$ & $40.9 \pm 2.0$ & $8.7 \pm 5.8$ & $76.7 \pm 8.4$ \\
\hline Total & $48.0 \pm 7.7$ & $44.9 \pm 9.3$ & $7.1 \pm 2.9$ & $(n=199)$ & $34.2 \pm 2.2$ & $56.4 \pm 7.8$ & $9.4 \pm 5.6$ & $(n=102)$ \\
\hline \multicolumn{9}{|l|}{ All layers } \\
\hline$\alpha 7(-)$ & $10.8 \pm 1.9$ & $13.1 \pm 2.7$ & $2.8 \pm 2.1$ & $26.7 \pm 5.7$ & $13.0 \pm 4.0$ & $15.3 \pm 2.5$ & $0.3 \pm 0.4$ & $28.9 \pm 4.3$ \\
\hline$\alpha 7(+)$ & $22.3 \pm 3.7$ & $42.8 \pm 6.3$ & $8.1 \pm 4.7$ & $73.3 \pm 5.7$ & $24.8 \pm 2.8$ & $41.6 \pm 3.4$ & $6.2 \pm 0.8$ & $71.1 \pm 4.3$ \\
\hline Total & $33.1 \pm 2.0$ & $55.9 \pm 3.6$ & $11.0 \pm 5.6$ & $(n=742)$ & $37.8 \pm 5.3$ & $56.0 \pm 4.0$ & $6.4 \pm 1.3$ & $(n=412)$ \\
\hline
\end{tabular}

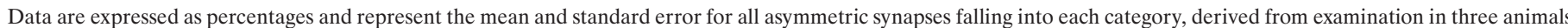

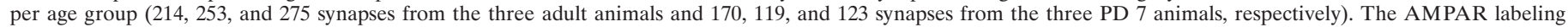

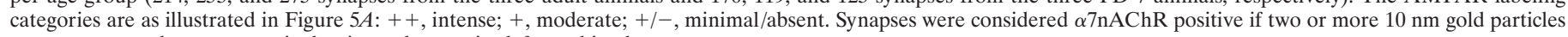
were seen over the postsynaptic density and synaptic cleft combined.

cortices (Fig. 2). This analysis showed that nearly $50 \%$ of the synaptic gold particles aggregated directly on the PSD (Fig. $2 A$ ). Moreover, analysis of gold particle distribution along the length of PSDs revealed that $\alpha 7 \mathrm{nAChR}$ immunoreactivity is distributed evenly, with a slightly higher concentration toward the center of the active zone captured within single ultrathin sections (Fig. $2 B$, left panel).

\section{Subcellular distribution of $\alpha 7 \mathrm{nAChR}$ in PD 7 cortex}

$\alpha 7$ nAChR labeling in PD 7 cortex was qualitatively similar to labeling in adult cortex, with extensive labeling of dendritic elements exhibiting asymmetric synapses (Figs. 2, 3A-E) and on the endoplasmic reticulum of neuronal perikarya (Fig. $3 F$ ). Where fortuitous planes of section revealed extensions of synaptic specializations away from the postsynaptic membrane or accentuated curvatures of the PSD (Fig. 3B, black arrow), immunogold particles followed these irregular PSD profiles.

Occasionally, gold particles clustered near plasma membranes lacking PSDs. These sites appeared to be nascent postsynaptic specializations, based on the alignment of the plasma membrane with that of the axon terminal (Fig. $3 E$, profile $N$ ). Axonal labeling at or near the presynaptic membrane was also seen (note Fig. $3 D$ in particular) but was not as prevalent as postsynaptic labeling.

The overall incidence of $\alpha 7 \mathrm{nAChR}$ immunoreactivity at asymmetric synapses in neonates was comparable to that seen in adults in that slightly more than two-thirds of all synapses were labeled, and immunoreactivity likewise did not vary significantly across layers (Table 1, PD 7, Total). Quantitative analysis of colloidal gold particles across presynaptic to postsynaptic distances from the cleft and along the lengths of PSDs of 270 representative synapses revealed a striking resemblance to the pattern seen for adult synapses (Fig. $2 A, B$ ).

Of the $\alpha 7$ nAChR-positive asymmetric synapses in PD 7 cortex,
$66.2 \%$ were axospinous, and they most likely represent synapses onto excitatory (pyramidal or spiny stellate) neurons; $10.3 \%$ were axon-shaft, and the remainder of postsynaptic profiles was not clearly identifiable (Table 2, PD 7). These figures closely reflect the overall distribution of synapses (Table 2, PD 7, Total, $\alpha 7 \mathrm{nAChR}$ positive plus $\alpha 7 \mathrm{nAChR}$ negative). The proportion of $\alpha 7$ nAChR-positive synapses that are axospinous is slightly higher in adulthood than in PD 7 cortex (Table 2, Adult and PD 7, $\alpha 7(+))$. The difference, which is not statistically significant, parallels an overall increase in the proportion of synapses (labeled plus unlabeled) that are axospinous (Table 2, Adult and PD 7, Total). This trend probably reflects the greater differentiation of adult cortex.

\section{AMPA receptor distribution by light microscopy}

The presence of $\alpha 7 \mathrm{nAChR}$ at the majority of postsynaptic sites of asymmetric, presumably excitatory synapses in neonatal as well as adult cortex [see also Lubin et al. (1999)], suggested that a subset of the silent synapses (i.e., those lacking AMPAR) reported previously might indeed be subject to postsynaptic nicotinic stimulation. We examined the distribution of AMPAR in relation to $\alpha 7 \mathrm{nAChR}$ using a combination of previously characterized antibodies against peptides corresponding to the $\mathrm{C}$ termini of GluR1 and GluR2/3 subunits to get an inclusive measure of the presence of AMPAR.

First, light microscopy was performed to confirm that GluR1/ 2/3 immunocytochemistry was adequate using tissue fixation conditions compatible with $\alpha 7 \mathrm{nAChR}$ immunolabeling. Light microscopy of AMPAR-stained adult cortex, visualized by HRPDAB (Fig. 4B), showed somatodendritic labeling of pyramidal and nonpyramidal neurons throughout the cortex, with large pyramidal cell bodies in layer $\mathrm{V}$ being especially prominent (Fig. $4 B$, thick bracket). Staining was relatively intense in layer I, because of nearly complete labeling of the neuropil, and relatively 
A

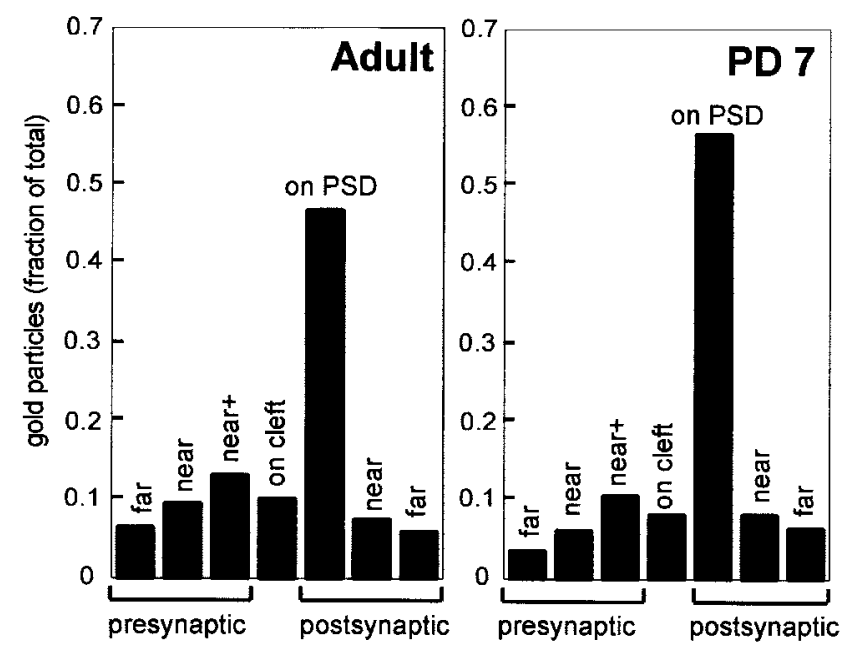

B

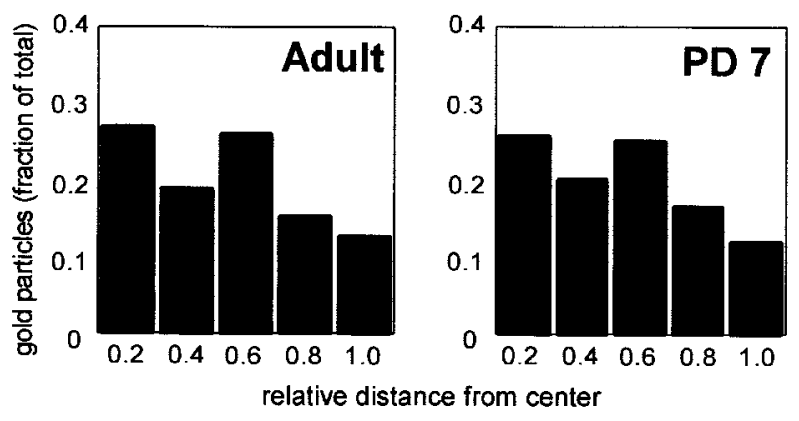

Figure 2. Synaptic $\alpha 7 \mathrm{nAChR}$ labeling is concentrated over the postsynaptic density. $A$, The distribution of $10 \mathrm{~nm}$ gold particles relative to the synaptic cleft was tallied for orthogonally sectioned asymmetric synaptic profiles (see Table 2 footnote) in all cortical layers combined for three animals of each age group. Both presynaptic and postsynaptic distances are expressed relative to the thickness of the postsynaptic density; i.e., on cleft or near+ is within one PSD width of the synaptic cleft; near and far are in adjacent zones of equal width. The data are from 420 profiles and 1721 particles for adult and 270 profiles and 1423 particles for PD 7. B, Distribution of $10 \mathrm{~nm}$ gold particles along the PSD is similar between PD 7 and adult tissue. For each age group, a random subset of relatively long orthogonally cut synaptic profiles ( $>250 \mu \mathrm{m}$ for PD $7 ;>300 \mu \mathrm{m}$ for adult) was drawn from all animals across all cortical layers, and the position of each gold particle was computed as a fraction of the distance from the center to the edge of the synapse, i.e., center $=0$, edge $=1$. Data are from 45 synapses and 195 gold particles for adult and 45 synapses and 292 gold particles for PD 7.

light in layer IV (Fig. 4B, thin bracket) and in the superficial part of layer VI. This laminar distribution pattern agreed with our expectations, on the basis of earlier reports on the laminar distribution of GluR1 and GluR2/3 examined separately (Petralia and Wenthold, 1992; Kharazia et al., 1996; Arai et al., 1997; Brennan et al., 1997; Petralia et al., 1997).

Labeling in PD 7 cortex showed less differentiation across layers (Fig. 4D), corresponding to the relatively undeveloped laminar pattern seen by Nissl staining (Fig. $4 C$ ). However, a dark band of immunoreactivity was appreciable in layer I (Fig. 4D,E), and strongly stained neuronal cell bodies were present in layers II/III (Fig. 4E), with less labeling in layer IV (Fig. 4D, thin bracket). Darkly labeled cell bodies were already apparent in layer V (Fig. $4 F$ ) and in the subplate zone (Fig. $4 G$ ) (Herrmann, 1996; Brennan et al., 1997).

\section{Subcellular distribution of AMPA receptors in adult cortex by electron microscopy}

EM examination (Fig. 5) confirmed the somatodendritic distribution of AMPARs. Patches of AMPAR labeling were seen within dendritic shafts, along the plasma membrane or over microtubules (Fig. $5 C$ ). HRP-DAB product occurred within dendritic spines (Fig. $5 A$ ), and relatively less occurred in the portion of the spine head away from the PSD [Fig. 5A, arrowhead, $C$, to the left and right of the spine apparatus $(S A)$ ]. In cases where spine necks were labeled (Fig. 5C, curved arrow), labeling was also associated with the membrane of the dendritic shaft from which the spine emerged.

The intensity of PSD labeling varied considerably (Fig. 5A, compare open arrow, curved arrow, and smaller solid arrow). In some instances, synapses with obvious AMPAR immunoreactivity, and those below the level of detectability (referred to as AMPAR negative), could be seen in close proximity within the same membrane-bound compartment (Fig. 5B), showing that the diffusibility of HRP-DAB product did not lead to unspecific labeling of all PSDs. Most of the asymmetric synapses had detectable postsynaptic AMPAR labeling in all cortical layers examined (Table 1, AMPAR ++, AMPAR + ), with the proportion diminishing to $52 \%$ in the deepest layer (Table 1, Adult, Total). In agreement with previous reports (Petralia and Wenthold, 1992), presynaptic AMPAR labeling was rarely seen.

\section{Localization of $\alpha 7 \mathrm{nAChR}$ relative to AMPA receptors at asymmetric synapses of adult cortex}

There was no significant correlation between the postsynaptic distribution of AMPAR and $\alpha 7 \mathrm{nAChR}$; i.e., the incidence of $\alpha 7$ nAChR labeling at intensely and moderately AMPAR-positive synapses ranged from two-thirds to three-quarters across the layers but was not significantly different from its incidence at AMPAR-negative synapses (Table 1). Individual synapses varied widely in their $\alpha 7 \mathrm{nAChR}$ and AMPAR content. For example, in Figure $5 A$, the most strongly AMPAR-positive synapse (open arrow) is also $\alpha 7 \mathrm{nAChR}$ positive (inset, circle), whereas the two other synapses, with less AMPAR immunoreactivity, are $\alpha 7 \mathrm{nAChR}$ negative (straight and curved arrow, respectively). Compare this with Figure $1 B$, where an intensely AMPARpositive, $\alpha 7 \mathrm{nAChR}$-negative synapse (curved arrow) is seen near an AMPAR-negative synapse with abundant $\alpha 7 \mathrm{nAChR}$ labeling (arrowheads).

\section{Distribution of AMPA receptor relative to $\alpha 7 \mathrm{nAChR}$ at synapses in PD 7 cortex}

The relative distribution of $\alpha 7 \mathrm{nAChR}$ and AMPAR in neonates resembled that of adult cortex (Fig. 6; compare with Fig. 5). The overall incidence of postsynaptic AMPAR labeling was comparable to that seen in adults; i.e., approximately two-thirds across all layers (Table 1). However, the intensity of AMPAR labeling in PD 7 synapses never approached that of the most intensely labeled synapses in the adult (Fig. 6A, compare with Fig. 5A). Colocalization of AMPAR and $\alpha 7 \mathrm{nAChR}$ was seen postsynaptically at PSDs of asymmetric synapses (Fig. $6 A$ ) and at extrasynaptic sites (Fig. 6B,C). As in adults, the incidence of $\alpha 7$ labeling was not significantly correlated with the degree of AMPAR labeling (Table 1). Specifically, neither the laminar position nor AMPAR immunoreactivity was a good predictor of $\alpha 7 \mathrm{nAChR}$ immunoreactivity. One notable point is that the synapses with 

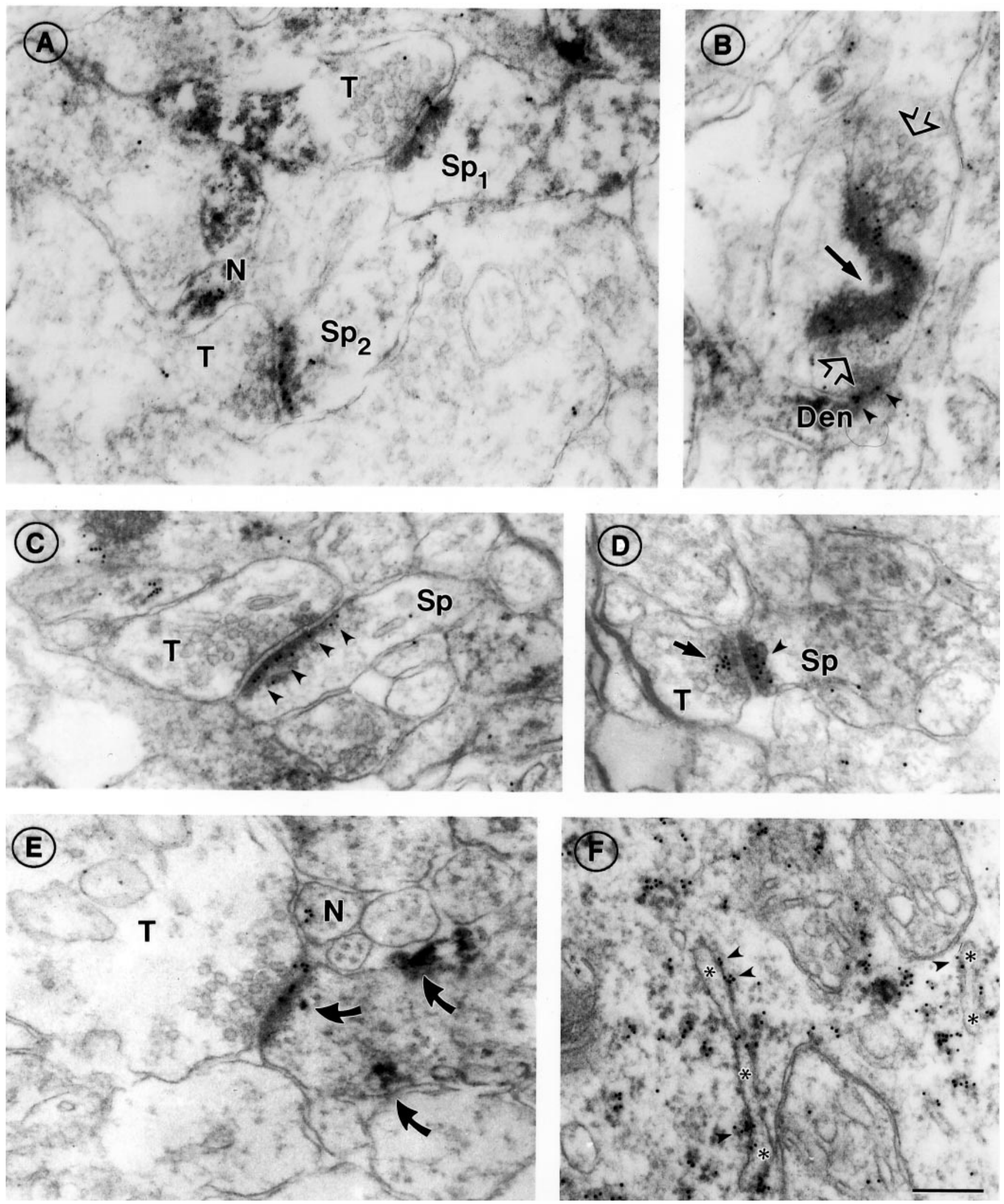

Figure 3. $\alpha 7 \mathrm{nAChR}$ immunoreactivity at asymmetric synapses of PD 7 somatosensory cortex. $A$, Two axon terminals $(T)$ forming synapses with spines $\left(S p_{1}, S p_{2}\right)$ in layer I, showing $\alpha 7 \mathrm{nAChR}$ labeling on the postsynaptic density (compare with Fig. 1$)$. The top synapse also shows gold particles on the synaptic cleft and at the presynaptic membrane. Also note the cluster of $\alpha 7 \mathrm{nAChR}$ labeling in the cytoplasm of an unidentified neurite $(N)$. $B$, En face view of a large irregular $\alpha 7 \mathrm{nAChR}$-positive postsynaptic density in layers II/III. Black arrow points to the curvature of the PSD. The axon terminal, identifiable by synaptic vesicles (open arrows), converges on the PSD from two directions and appears to form another synapse below with a second dendritic compartment (Den), also $\alpha 7 \mathrm{nAChR}$ positive (arrowheads). C, $D$, Axospinous synapses in layers II/III; compare the exclusively postsynaptic labeling in $C$ (arrowheads) with the discrete clusters of presynaptic (arrow) and postsynaptic (arrowhead) labeling in D. (Figure legend continues.) 
Table 2. Identity of postsynaptic profiles (dendritic spine or dendritic shaft) exhibiting synapses

\begin{tabular}{lrllll} 
& \multicolumn{1}{l}{ Adult } & & PD 7 & \\
\cline { 2 - 3 } & \multicolumn{1}{c}{$\alpha 7(+)$} & Total & & $\alpha 7(+)$ & Total \\
\hline Spine & $73.4 \pm 5.7$ & $71.5 \pm 6.9$ & & $66.2 \pm 5.7$ & $67.2 \pm 7.3$ \\
Shaft & $9.4 \pm 4.8$ & $10.1 \pm 3.1$ & & $10.3 \pm 7.4$ & $11.2 \pm 7.9$ \\
Unidentified & $17.2 \pm 2.9$ & $18.5 \pm 4.6$ & & $23.5 \pm 4.5$ & $21.6 \pm 4.0$ \\
& & $(n=420)$ & & $(n=270)$
\end{tabular}

Note the prevalence of axon-spine junctions among both $\alpha 7 \mathrm{nAChR}$-positive and total asymmetric synapses in both age groups. Data (expressed as percentage of the total for each column) were gathered from a subset of all synapses examined in this study, including only synaptic profiles orthogonal to the section plane (those where the synaptic cleft was visible along the entire profile in electron micrographs). This subset of synapses was also used in Figures 2 and 7-9. Mean and standard error are derived from three animals in each age group $(124,136$, and 160 synapses from the three adult animals and 116, 71, and 82 synapses from the three PD 7 animals, respectively). Variations across cortical layers within each age group were not statistically significant, and data for all cortical layers are combined in the table.

intense AMPAR immunoreactivity were $\alpha 7 \mathrm{nAChR}$ immunoreactive almost without exception. However, a substantial fraction of all synapses (22\% in the adult group, $25 \%$ in PD 7, combined across all layers) were AMPAR negative but $\alpha 7 \mathrm{nAChR}$ positive and might therefore be candidate sites for cholinergic modulation of NMDAR-containing, AMPAR-lacking silent synapses.

\section{Quantitative analysis of postsynaptic $\alpha 7 n A C h R$ immunoreactivity}

A count of $10 \mathrm{~nm}$ gold particles corresponding to $\alpha 7 \mathrm{nAChR}$ labeling over discrete labeled synapses confirmed our qualitative observation that the density of $\alpha 7 \mathrm{nAChR}$ labeling was higher in neonatal than in adult synapses (Fig. 7). To simplify the analysis, we included only orthogonally sectioned synapses and used PSD length, rather than PSD area, as a measure of the size of each profile. Considerable variability in the density of labeling (Fig. 7, $y$-axis) and lengths of PSDs (Fig. 7, $x$-axis) was noted among both adult and PD 7 populations of synapses. A weak positive correlation was seen between synapse length and the number of $10 \mathrm{~nm}$ gold particles per synapse, regardless of the degree of AMPAR labeling present: AMPAR ++, AMPAR +, and AMPAR+/(Fig. 7, compare panels). Across the three categories of AMPAR labeling, the density of $\alpha 7 \mathrm{nAChR}$ labeling was consistently greater for PD 7 synapses than for adult synapses (Fig. 7, compare the slopes of the linear regression plots). This difference between PD 7 and adult was statistically significant within each category of AMPAR labeling ( $p<0.05$; two-tailed $t$ test) and likewise within each cortical layer examined (superficial, middle, and deep, with all categories of AMPAR immunoreactivity combined; data not shown). To assess the consistency of results between experimental animals, pairwise $t$ tests were performed among animals of the same age group and within the same cortical layer. Of 18 possible comparisons, 17 yielded no significant difference between animals $(p>0.5)$, whereas one pair (in PD 7, deep layers) was significantly different $(p=0.003)$. We did not detect significant layerdependent differences in the density of $\alpha 7 \mathrm{nAChR}$ labeling, and data from all cortical layers are combined in Figure 7 and subsequent figures.

We examined whether the variation in density of $\alpha 7 \mathrm{nAChR}$ labeling was the result of random variations in the degree of labeling or whether it might reflect an underlying heterogeneity of $\alpha 7 \mathrm{nAChR}$ density. Previous EM immunocytochemical studies have modeled the detection of antigen in ultrathin sections as a Poisson process (Kharazia and Weinberg, 1999; Racca et al., 2000). In Figure 8, the density of $\alpha 7 \mathrm{nAChR}$ labeling at discrete synapses is seen to differ in two ways from a Poisson distribution around a single mean. (1) In both adult and PD 7 data sets, there is a disproportionately large number of postsynaptic profiles without gold particles [Fig. 8, leftmost bin in each histogram; compare black bar (experimental) with gray bar (Poisson)], and this population is larger in the PD 7 group than in the adult group. (2) The PD 7 group contains a statistically distinct subpopulation of 21 synaptic profiles with a relatively high density of $\alpha 7 \mathrm{nAChR}$ (50 or more particles per micrometer); these profiles constitute $8.9 \%$ of the total in the PD 7 data set versus $2.4 \%$ in the adult data set.

The data for PD 7 are presented as a scatter plot in Figure 9, subdivided according to the degree of AMPAR labeling at each synapse. The plot shows that the group of profiles with 50 or more gold particles per micrometer consisted mostly of those with relatively short active zones ( $250 \mathrm{~nm}$ or less) and without intense AMPAR labeling. Eleven of these synapses belonged to the superficial layers, four belonged to the middle layers, and six belonged to the deep layers. Fourteen of the synapses were judged to be axospinous, whereas one (in layer VI) was axonshaft, and six could not be classified as one or the other. Of these densely $\alpha 7 \mathrm{nAChR}$-labeled synapses, 14 were found in animal one, 3 were found in animal two, and 4 were found in animal three.

\section{DISCUSSION}

Prevalence of postsynaptic $\alpha 7 \mathrm{nAChR}$ in both adult and neonatal somatosensory cortex suggests a widespread role in excitatory transmission

A large body of work documents the influence of cholinergic activity on experience-dependent plasticity in cortical receptive field properties (Sillito and Kemp, 1983; Kilgard and Merzenich, 1998). For example, acetylcholine can switch the flow of excitatory activity from columnar to intercolumnar connections through the muscarinic receptors (Xiang et al., 1998) while also boosting the activity of thalamic (glutamatergic) afferents through nicotinic receptors (Gil et al., 1997).

To the best of our knowledge, ours is the first study of the ontogeny of $\alpha 7 \mathrm{nAChR}$ at the EM level. $\alpha 7 \mathrm{nAChR}$ was found at most postsynaptic densities of synapses identified as glutamatergic by the presence of AMPAR (GluR1, GluR2, and GluR3) subunits and by morphology in both adults and neonates. This implies that the contribution made by $\alpha 7 \mathrm{nAChR}$ in excitatory synaptic transmission in neocortex may be much greater than was recognized previously. We observed dually $\alpha 7 \mathrm{nAChR}$-positive

\footnotetext{
(Figure legend continued.) The sparse, pleiomorphic vesicles seen in the axon terminal $(T)$ in $C$ are characteristic of immature synapses. E, An $\alpha 7$ nAChR-positive synapse in layer VI. As in $A$, a nonsynaptic cluster of $\alpha 7$ label is seen in an adjacent neurite $(N)$; also present in the postsynaptic compartment are patches of HRP-DAB reaction product indicating AMPAR labeling (curved arrows; compare with Fig. $1 B$; see also Fig. 6). $A$, $D$, and especially $E$ show terminals with large cytoplasmic volumes devoid of vesicles. This is a recurrent feature of PD 7 neuropil. $F, \alpha 7 \mathrm{nAChR}$ labeling of rough endoplasmic reticulum (ER) in a pyramidal cell body of layers II/III. Note the predominantly cytoplasmic location of gold particles (arrowheads; compare with Fig. $1 C$ ). Asterisks denote the ER lumen. Scale bar (shown in $F$ for $A-F$ ): $200 \mathrm{~nm}$.
} 

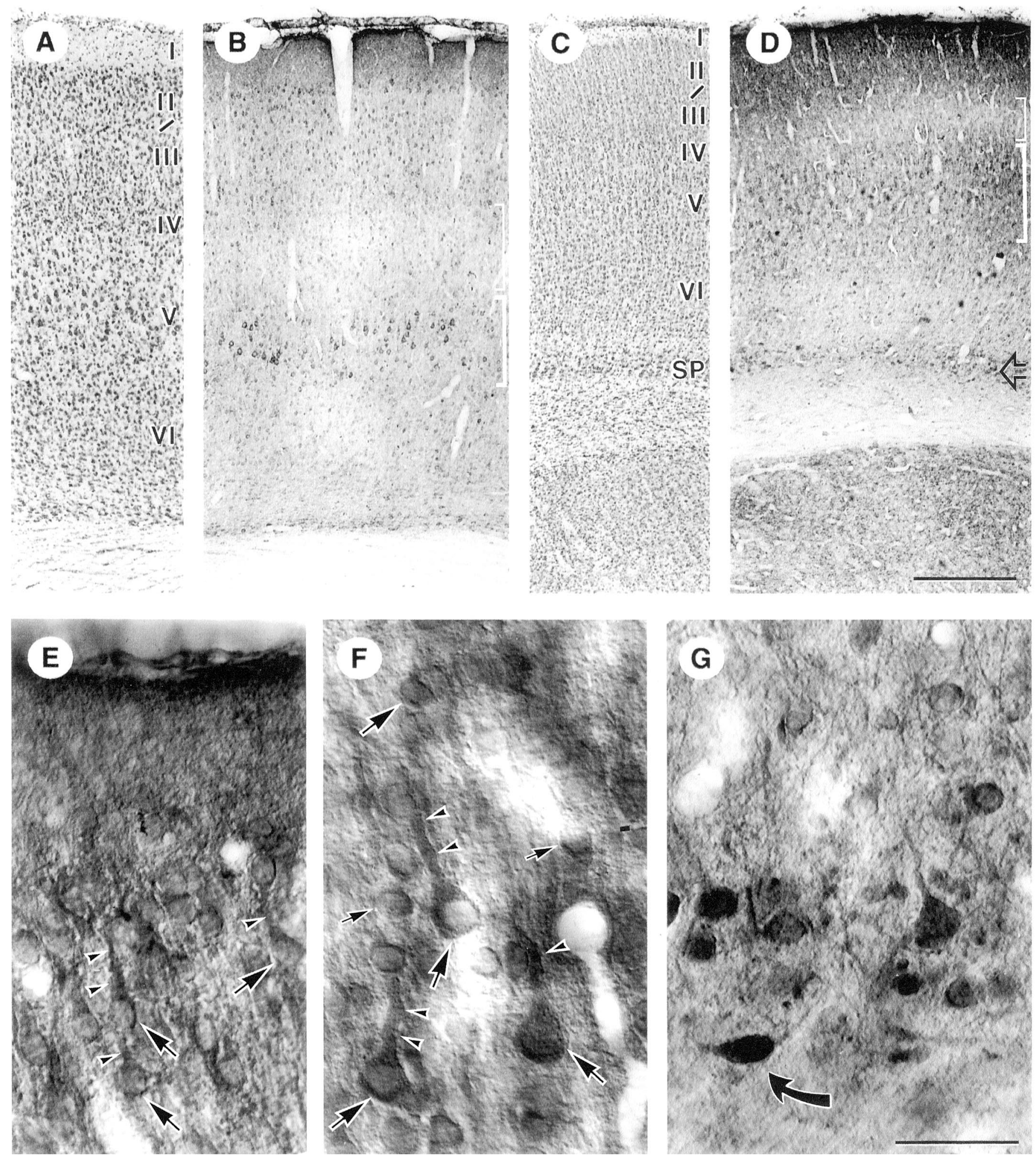

Figure 4. Light micrographs of AMPAR immunoreactivity (GluR1/2/3 subunits) in adult $(A, B)$ and PD $7(C-G)$ somatosensory cortex. $A$, Nissl stain of adult cortex shows location of layers. $B$, HRP-DAB staining for AMPAR: cell bodies and apical dendrites of layer $\mathrm{V}$ pyramidal neurons are most prominent (thick bracket), but staining is appreciable in all neuronal cell types and across all layers. Staining of layer I neuropil is relatively dense, whereas staining is relatively light in layer IV (thin bracket). $C$, Nissl stain of PD 7 cortex. Note that the cell bodies are more densely packed and the laminar boundaries less well defined than in the adult. $S P$, Subplate region. $D$, AMPAR distribution at PD 7: note diff use neuropil labeling in layers I and II/III and relatively light staining of layer IV (thin bracket), staining of layer V pyramidal cell bodies (thick bracket), and darkly stained cell bodies in the subplate layer (open arrow). $E-G$, Higher magnification views of AMPAR staining in superficial layers $(E)$, layer V $(F)$, and the subplate layer $(G)$ of PD 7 somatosensory cortex. Note labeling of pyramidal cell bodies (large arrows), apical dendrites (arrowheads), and smaller interneuronal cell bodies (small arrows); in $G$, note dark staining of atypically shaped cell body in the subplate region (curved arrow). Scale bars: $A-D, 400 \mu \mathrm{m} ; E-G, 40 \mu \mathrm{m}$. 

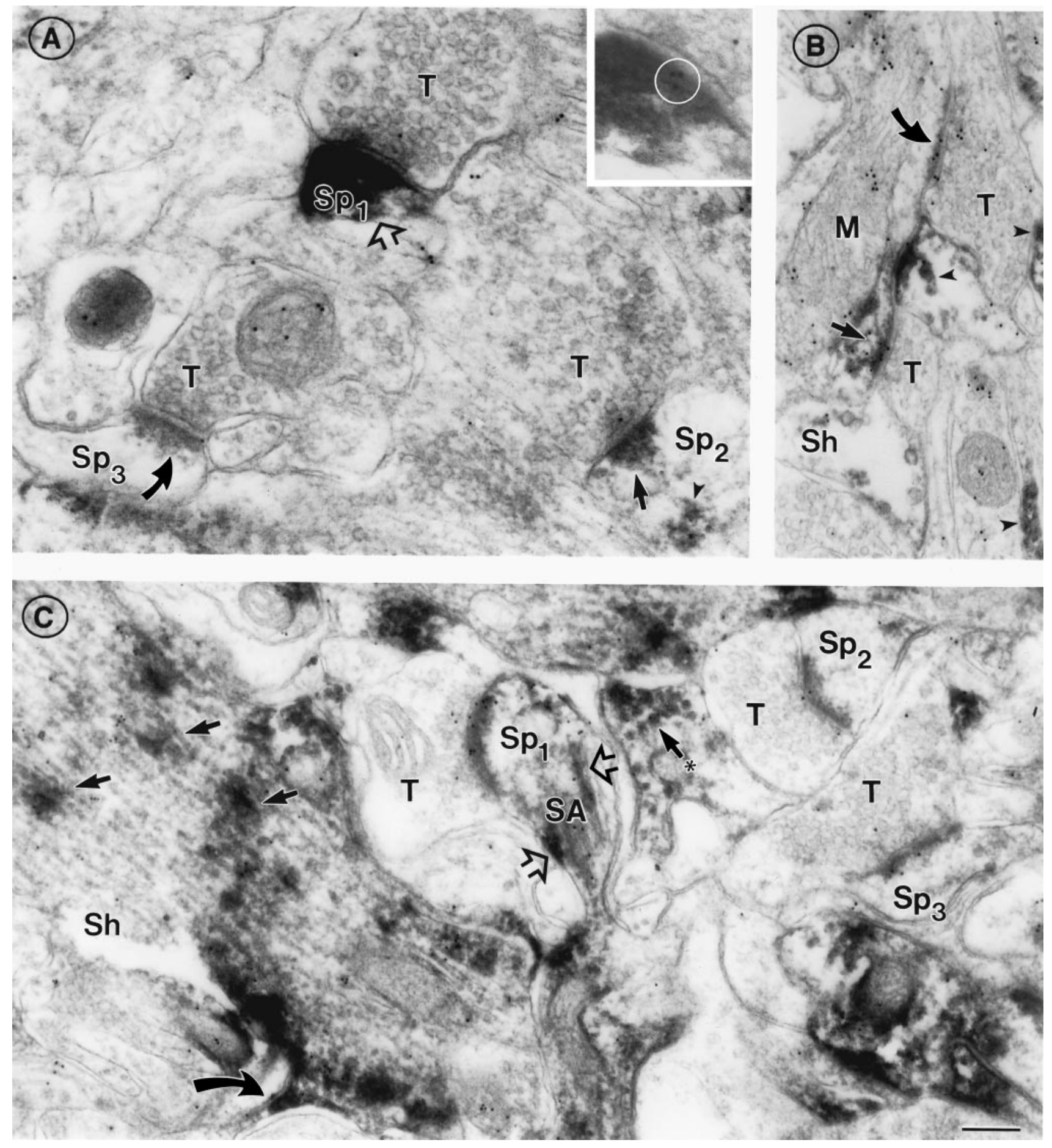

Figure 5. Subcellular distribution of AMPAR immunoreactivity is mostly independent of $\alpha 7 \mathrm{nAChR}$ distribution in adult cortex. $A$, Three axon terminals $(T)$ forming synapses with spines in layer I demonstrate intense (AMPAR ++ ; open arrow in $S p_{1}$ ), moderate (AMPAR + ; filled straight arrow in $S p_{2}$ ), or minimal/absent postsynaptic AMPAR labeling (AMPAR+/-; curved arrow in $S p_{3}$ ), respectively, visualized as HRP-DAB reaction product. These assignments correspond to the three-level classification scheme used in this study for statistical analysis of AMPAR labeling (Table 1). The PSD in $\mathrm{Sp}_{1}$ also contains three $10 \mathrm{~nm}$ gold particles representing $\alpha 7 \mathrm{AChR}$ labeling; these are reproduced in the inset (circled) with greater magnification and reduced contrast for the sake of visualization. In $S p_{2}$, note non-synapse-associated AMPAR (arrowhead) in the spine head. $B$, Two axon terminals ( $T$ ) in layers II/III form asymmetric synapses with a single dendritic shaft [(Sh) identifiable as such by its size and the presence of a large mitochondrion $(M)$ ]. Note that the postsynaptic density of the bottom synapse is labeled for AMPAR (straight arrow), and the top synapse is unlabeled (curved arrow). Both postsynaptic densities are also $\alpha 7 \mathrm{nAChR}$-positive $(10 \mathrm{~nm}$ gold particles). $C$, Independent distribution of $\alpha 7 \mathrm{nAChR}$ and AMPAR labeling in a dendritic shaft (Sh) and several axospinous synapses in layers II/III. All three show minimal AMPAR labeling but varying degrees of $\alpha 7 \mathrm{nAChR}$ labeling. Patches of AMPAR immunoreactivity are visible over microtubules running lengthwise in the shaft (straight arrows) and cut in cross section in another dendrite nearby (arrow with asterisk). AMPAR is also seen in the lower spine neck (curved arrow) and along the spine apparatus (SA) in $\mathrm{Sp}_{1}$ (open arrows). Note the absence of AMPAR labeling in presynaptic terminals. $\alpha 7 \mathrm{nAChR}$ labeling $(10 \mathrm{~nm}$ gold particles $)$ is present both presynaptically and postsynaptically, and is also seen on the spine apparatus and within the dendritic shaft. Scale bar (shown in $C$ ): $A, 250 \mathrm{~nm} ;$ inset, $400 \mathrm{~nm} ; B, C, 200 \mathrm{~nm}$. 

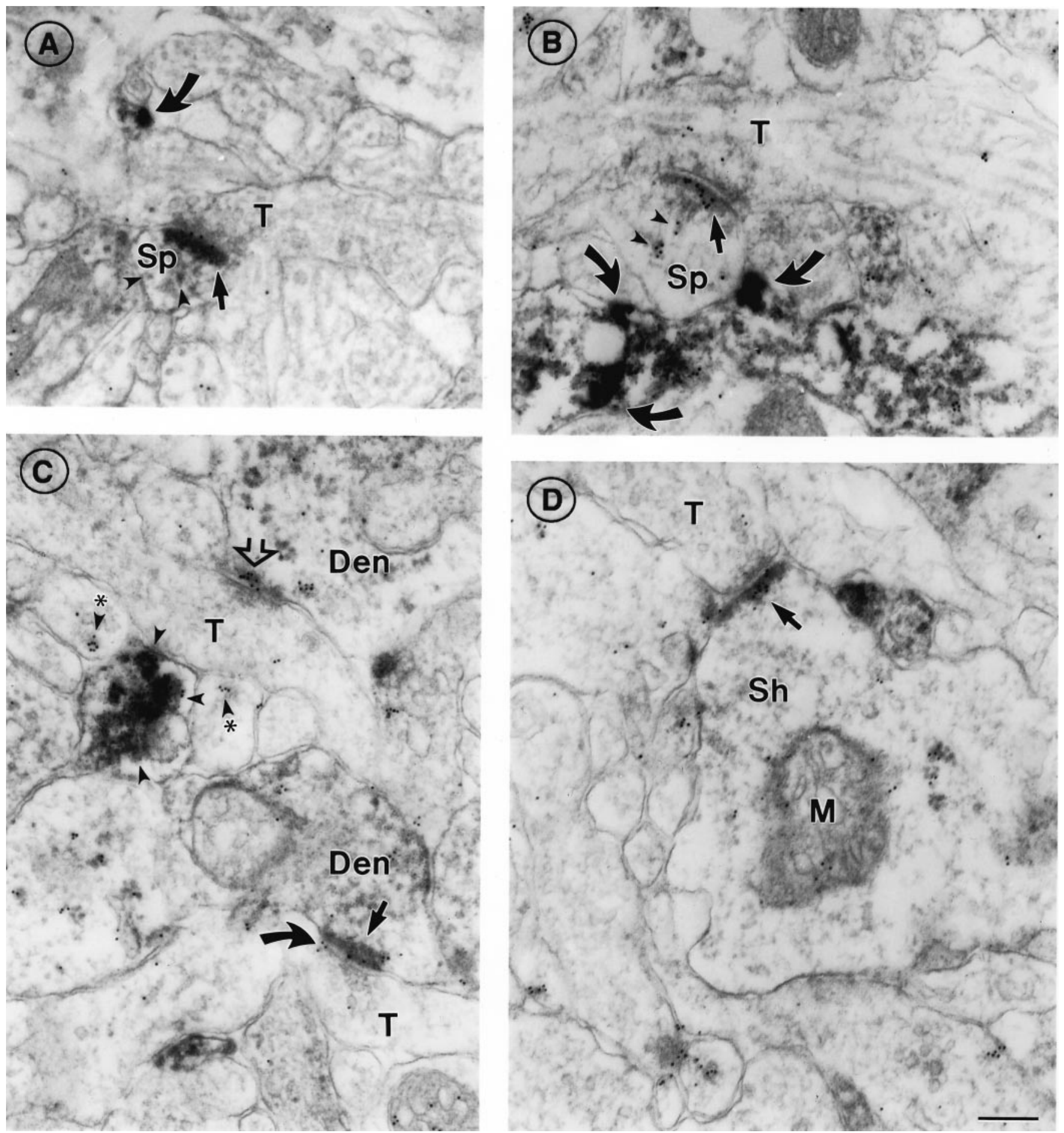

Figure 6. Subcellular distribution of AMPAR immunoreactivity relative to $\alpha 7 \mathrm{nAChR}$ immunoreactivity in PD 7 cortex resembles that seen in adult cortex. $A$, An axon terminal ( $T$ ) forming a synapse with a spine $(S p)$ in layer I, exhibiting both AMPAR (HRP-DAB reaction product) and $\alpha 7 \mathrm{nAChR}$ $(10 \mathrm{~nm}$ gold) reactivity on the postsynaptic density (straight arrow). Small patches of relatively less intense AMPAR staining are seen elsewhere in the postsynaptic compartment (arrowheads). An unidentified process nearby (curved arrow) is also positive for both AMPAR and $\alpha 7 \mathrm{nAChR}$. B, An example of an $\alpha 7$ nAChR-positive, AMPAR-negative PSD (straight arrow) in layer I; compare the dense AMPAR staining of an adjacent neuronal process (curved arrows). $\alpha 7 \mathrm{nAChR}$ reactivity is also seen over electron-dense material located away from the PSD (arrowheads). $C$, Axon terminals $(T)$ forming AMPAR-positive (black arrow) and AMPAR-negative (open arrow) synapses in layers II/III; both show $\alpha 7$ nAChR reactivity over the postsynaptic density, whereas the AMPAR-positive synapse shows $\alpha 7 \mathrm{nAChR}$ associated with the presynaptic membrane as well (curved arrow). The dendritic elements (Den) are difficult to classify as spine or shaft. Nearby neuronal processes show clusters of $\alpha 7 \mathrm{nAChR}$ labeling with (arrowheads) and without (arrowheads with asterisks) associated AMPA receptor labeling. D, AMPAR-positive, $\alpha 7 \mathrm{nAChR}$-positive synapse (arrow) on a dendritic shaft (Sh) [note mitochondrion $(M)]$ in layer VI. Scale bar (shown in $D$ for $A-D$ ): $200 \mathrm{~nm}$. 

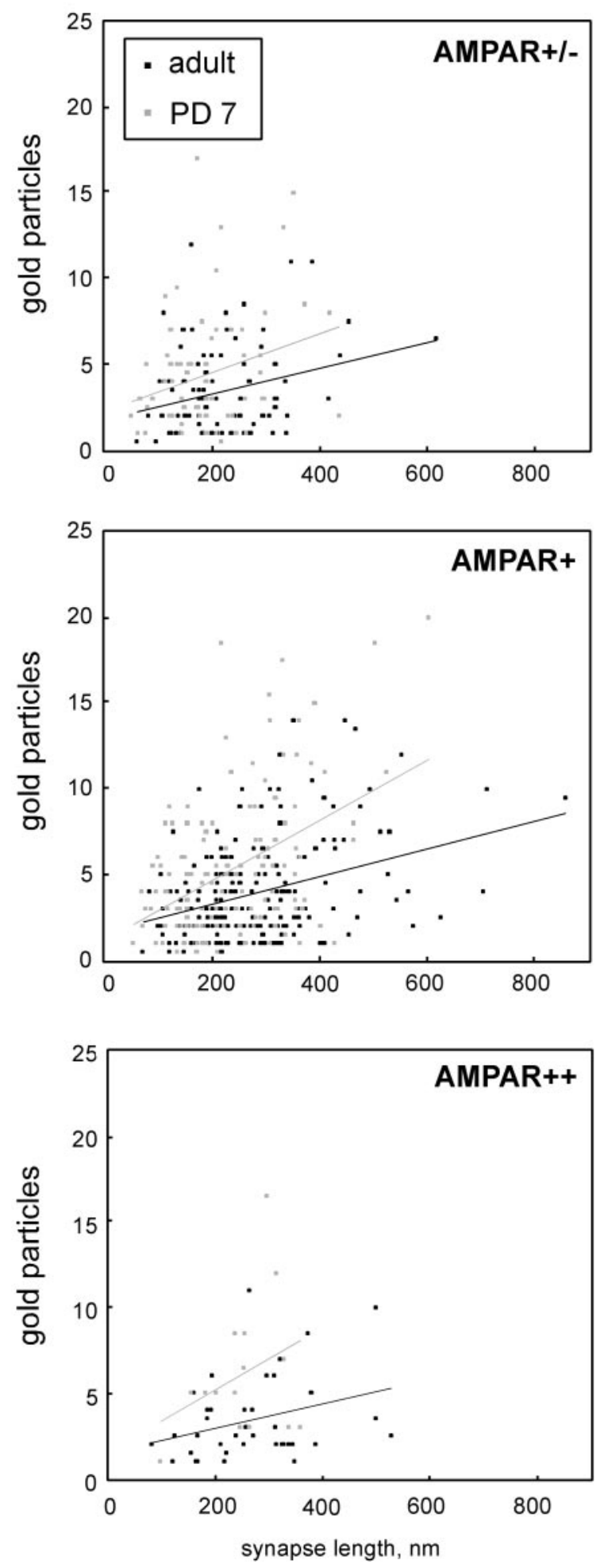

Figure 7. Scatter plots relating synaptic profile length to amount of postsynaptic $\alpha 7 \mathrm{nAChR}$ labeling, divided according to the degree of AMPAR labeling: minimal/absent (AMPAR $+/-$ ), moderate (AMPAR + ), or intense (AMPAR ++ ). See Figure $5 A$ for an electron micrograph illustrating these categories. Gray symbols represent PD 7, and black symbols represent adult synapses. Synapses across all cortical layers and from three animals of each group are combined in each plot. $\alpha 7 \mathrm{nAChR}-$ negative profiles and obliquely sectioned profiles were excluded from the count. $\alpha 7 \mathrm{nAChR}$ labeling was calculated by adding the number of $10 \mathrm{~nm}$ gold particles on the PSD to one-half the number of particles on the and AMPAR-positive synapses not confined to the thalamorecipient zone (layer IV) but also present in the supragranular and infragranular layers. Moreover, most of these synapses were axospinous. Axospinous junctions are unlikely to be on interneurons, the class previously identified as the main site of postsynaptic nicotinic activity (Alkondon et al., 1998; Frazier et al., 1998a,b) but instead are on excitatory neurons, i.e., pyramidal or stellate cells. This conclusion is strengthened by similar findings reported in adult guinea pig prefrontal cortex (Lubin et al., 1999) and in adult rat hippocampal area CA1 (Fabian-Fine et al., 2001). In the latter case, $\alpha 7 \mathrm{nAChR}$ was detected postsynaptically at almost all asymmetric synapses examined. This study used the same antibody as the present one (mAb 306 from Sigma/RBI), but in conjunction with a different EM processing protocol (freeze-substitution followed by embedding in Lowicryl). Despite the differences in EM processing techniques, both sets of data concur in demonstrating strong postsynaptic $\alpha 7 \mathrm{nAChR}$ immunoreactivity.

Our results and those of Fabian-Fine et al. (2001) also concur in visualizing substantial $\alpha 7 \mathrm{nAChR}$ immunoreactivity at extrasynaptic sites within dendritic spines (e.g., in association with the spine apparatus) and on the endoplasmic reticulum within neuronal cell bodies, indicating a large reserve pool and rapid, possibly activity-dependent turnover and trafficking of $\alpha 7 \mathrm{nAChR}$. Our results extend previous light microscopic immunocytochemical data on $\alpha 7 \mathrm{nAChR}$ localization to neuronal cell bodies and dendrites (Dominguez del Toro et al., 1994) and radioligand binding data obtained with $\alpha$-bungarotoxin (Barrantes et al., 1995).

The activity of postsynaptic nicotinic receptors has been well documented in the peripheral nervous system (cf. Jacob and Berg, 1983; Zhang et al., 1994), and the existence of $\alpha 7 \mathrm{nAChR}$ mediated EPSPs was recently reported in hypothalamus (Hatton and Yang, 2002). In hindsight, it is surprising that much of the past electrophysiological evidence for postsynaptic nicotinic effects in forebrain was confined to hippocampal GABAergic (aspiny) interneurons (cf. Alkondon et al., 1998; Frazier et al., 1998a,b). Evidence for postsynaptic nicotinic activity in excitatory neurons of hippocampus (Hefft et al., 1999) and neocortex (Roerig et al., 1997; Chu et al., 2000) is comparatively sparse. A possible explanation for why cortical glutamatergic neurons have not shown more prominent $\alpha 7 \mathrm{nAChR}$ currents by somatic recordings is that $\alpha 7 \mathrm{nAChR}$ might act through metabolic pathways triggered by $\mathrm{Ca}^{2+}$ influx (for review, see Edwards, 1995) rather than through membrane depolarization. Alternatively, perhaps the depolarizing action of $\alpha 7 \mathrm{nAChR}$ is confined to spines, especially on the distal, fine branches of dendrites (e.g., in layers I and II), making these currents relatively more difficult to detect in whole-cell recordings. In addition, decreases in extracellular $\mathrm{Ca}^{2+}$ during periods of high neuronal activity (Vernino et al., 1992; Amador and Dani, 1995), the relatively low agonist affinity and high desensitization rate of $\alpha 7 \mathrm{nAChR}$ (Albuquerque et al., 1997), and the progressive glial ensheathment of excitatory synapses in maturing animals (Ling and Leblond, 1973; Parnavelas et

$\leftarrow$

synaptic cleft. Total least-squares regression line is shown for each data set. Coefficients of correlation $\left(R^{2}\right)$ are 0.088 for AMPAR ++ adult $(n=$ 42), 0.105 for AMPAR + + PD $7(n=15), 0.089$ for AMPAR + adult $(n=$ 209), 0.196 for AMPAR + PD $7(n=129), 0.075$ for AMPAR+/- adult $(n=88)$, and 0.070 for AMPAR $+/-\operatorname{PD} 7(n=67)$. 

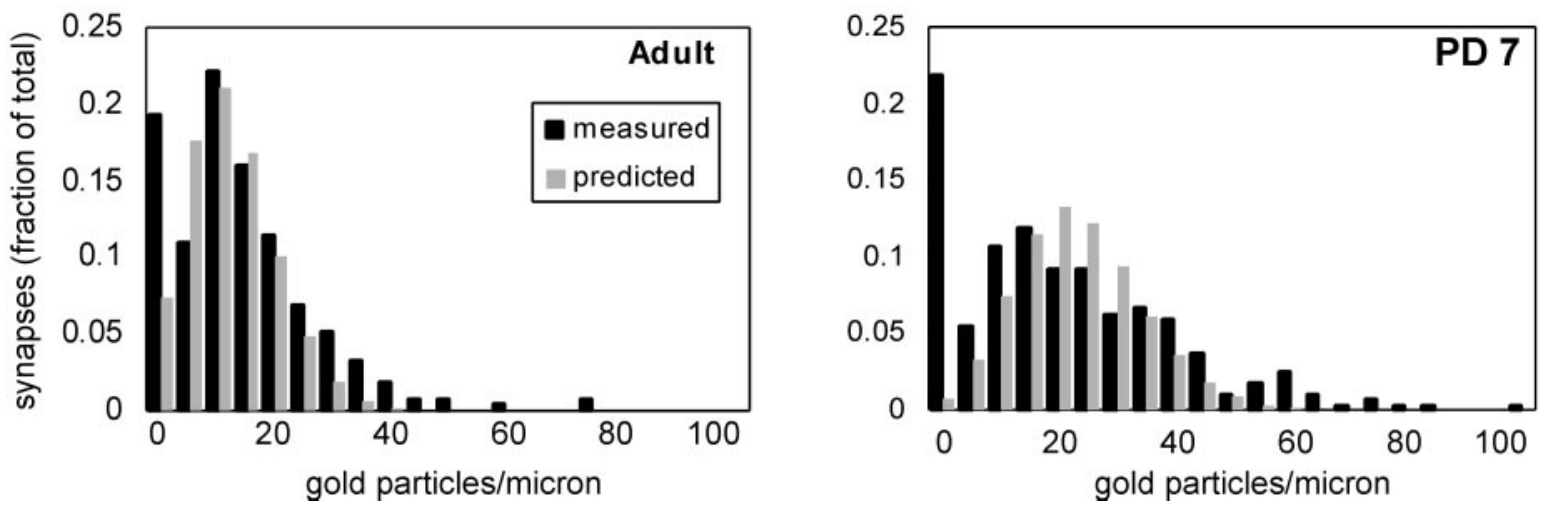

Figure 8. Histograms showing the density of $\alpha 7 \mathrm{nAChR}$ labeling on postsynaptic profiles (black bars) in all adult versus PD 7 synapses. The data are the same as those used to generate Figure 2, except that unlabeled synapses are included (leftmost bin of each panel). Theoretical Poisson distributions ( gray bars) were obtained by fitting the experimental data over a restricted range [bin range 5-100 for adult; bin range 5-50 for PD 7 by total least-squares, using a procedure written in MATLAB (Math Works, Natick, MA)]. The fit therefore excluded unlabeled synapses (leftmost column of each graph) and neonatal synapses with $>50$ gold particles per micrometer. The mean of the Poisson distribution was 23.5 for PD 7 and 15.0 for adult. Experimental data did not differ significantly from the theoretical Poisson values over the included range ( $p>0.05$; Kolmogorov-Smirnov test). Experimental data from PD 7 for bin ranges 5-100 (i.e., including synapses with $>50$ gold particles per micrometer) differed significantly from a Poisson distribution fit to that range of bins ( $p<0.05$; Kolmogorov-Smirnov test; graph not shown). The percentage of "truly" negative synapses (measured value minus Poisson value, left-hand bin of each graph) was $12.0 \%$ for adults and $21.1 \%$ for PD 7). $n=420$ synapses for adult; $n=270$ synapses for PD 7. The adult sample included one profile with 179 particles per micrometer that was excluded from the statistical analysis.

Figure 9. Density of $\alpha 7 \mathrm{nAChR}$ labeling as a function of synapse length in PD 7 synapses. Data points are grouped according to the degree of postsynaptic AMPAR labeling: intense (black squares), moderate ( gray squares), or minimal/absent (white squares). Points above the dotted line correspond to those to the right of the 50 particle per micrometer bin (inclusive) in the PD 7 histogram (Fig. 8). Note the relative absence of larger synaptic profiles and intensely AMPARpositive synapses in this group. The data set is the same one used for PD 7 in Figure 7.

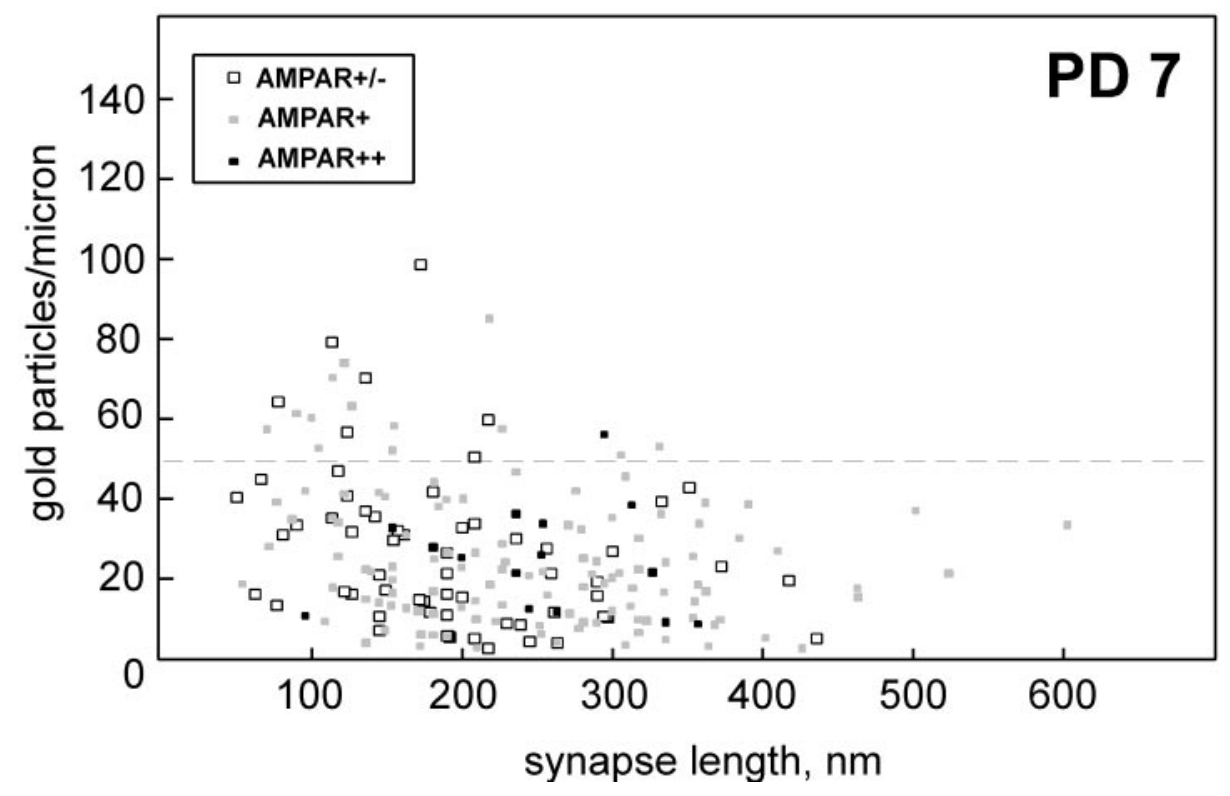

al., 1983) could have obscured the biophysical detection of $\alpha 7 \mathrm{nAChR}$.

\section{Many of the $\alpha 7 n A C h R-e n r i c h e d$ synapses at PD 7 are AMPA receptor-negative profiles with short active zones}

Comparison with a theoretical Poisson distribution [see similar analyses by Kharazia and Weinberg (1999), Petralia et al. (1999), Takumi et al. (1999), and Racca et al. (2000)] indicates that a fraction of all asymmetric synapses was truly $\alpha 7 \mathrm{nAChR}$ negative in both adults and neonates, whereas most synapses showed a moderate density of $\alpha 7 \mathrm{nAChR}$ immunoreactivity. A smaller fraction, in neonates only, possessed a distinctly higher density of $\alpha 7 \mathrm{nAChR}$. The majority of these $\alpha 7 \mathrm{nAChR}$-enriched profiles appeared to represent synapses with relatively small active zones. The alternative possibility, namely that these profiles represented sections through the periphery of larger synapses, with $\alpha 7 \mathrm{nAChR}$ concentrated toward the edge of the PSD (i.e., in a ring), was ruled out because we did not see this distribution of $\alpha 7 \mathrm{nAChR}$ either in individual PSDs viewed en face or in a random sample of larger PSDs viewed in cross section (Fig. 2B).

On the basis of the observation that synaptic AMPAR content increases steeply with active zone length in adult S1 cortex, other authors have proposed that synapses with the shortest active zones may be essentially AMPAR negative (Kharazia and Weinberg, 1999), and potentiation of these synapses may involve the activity-dependent insertion of AMPAR (Liao et al., 1995; Shi et al., 1999). In the present study, many of the $\alpha 7 \mathrm{nAChR}$-enriched synapses with short active zones in the neonatal group were not detectably immunoreactive for GluR1, GluR2, or GluR3 and may indeed be functionally AMPAR negative. Such $\alpha 7 \mathrm{nAChR}$ enriched, AMPAR-negative synapses may rely on $\alpha 7 \mathrm{nAChR}$ mediated depolarization to relieve the voltage-dependent $\mathrm{Mg}^{2+}$ 
blockade of NMDAR. Perhaps this is the same population of synapses shown by Aramakis and colleagues (Aramakis and Metherate, 1998; Aramakis et al., 2000) to be silent (AMPAR lacking) immature synapses in which NMDA current is enhanced by an $\alpha 7 \mathrm{nAChR}$ - or NMDAR-mediated mechanism. These results pointed clearly to a presynaptic effect (enhancement of glutamate release), whereas ours show a mostly postsynaptic concentration of $\alpha 7 \mathrm{nAChR}$ and a lesser presynaptic concentration. This difference might be explained by a mechanism in which a postsynaptic $\alpha 7 \mathrm{nAChR}$-mediated influx of $\mathrm{Ca}^{2+}$ leads to the activation of the $\mathrm{Ca}^{2+} /$ calmodulin-dependent neuronal nitric oxide synthase (NOS); the product, nitric oxide, is a retrograde messenger that could enhance presynaptic glutamate release $(\mathrm{Cu}-$ deiro and Rivadulla, 1999; for review, see Contestabile, 2000). Our earlier findings on the subcellular localization of NOS support this idea, because NOS was found within NMDAR-positive spines forming asymmetric axospinous junctions (Aoki et al., 1997, 1998).

\section{Possible interactions between $\alpha 7 \mathrm{nAChR}$ and postsynaptic scaffolding proteins}

The clustering of $\alpha 7 \mathrm{nAChR}$ at PSDs of asymmetric synapses implies that $\alpha 7 \mathrm{nAChR}$ is retained at the PSD through interaction with other PSD components. Studies of the neuromuscular junction have identified an extracellular protein, agrin (McMahan, 1990; Sanes and Lichtman, 1999), which is essential for nAChR clustering at the motor endplate via the transmembrane kinase MuSK (Glass et al., 1996) and the cytoplasmic protein rapsyn (Apel et al., 1997). Mice deficient in agrin showed no abnormalities in glutamatergic and GABAergic synapse formation (Serpinskaya et al., 1999). Likewise, rapsyn deficiency abolished neuromuscular but not neuronal nAChR clustering (Apel et al., 1997; Feng et al., 1998). Therefore, $\alpha 7 \mathrm{nAChR}$ may interact with known or yet unknown scaffolding proteins of glutamatergic CNS synapses. An interaction was reported recently (Huh and Fuhrer, 2001) between $\alpha 7 \mathrm{nAChR}$ and PICK1, a PDZ domain-containing cytoplasmic protein that promotes clustering of AMPARs (Dev et al., 1999; Xia et al., 1999). We found, however, that $\alpha 7 \mathrm{nAChR}$ distribution at asymmetric synapses is independent of AMPAR distribution. This suggests that $\alpha 7 \mathrm{nAChR}$ and AMPAR at synapses are not bound to a common postsynaptic scaffolding protein. $\alpha 7 \mathrm{nAChR}$ and AMPAR may interact through PICK1 or other interacting proteins at extrasynaptic sites, e.g., during intracellular assembly and targeting.

\section{AMPAR immunoreactivity in neonatal versus adult cortex}

The fact that the most intense AMPAR immunoreactivity was seen only in adult cortex may reflect the progressive acquisition of AMPAR subunits over postnatal development (Petralia et al., 1999). In both adult and neonatal cortices, we saw wide variations in AMPAR immunoreactivity among thick PSDs, lending support to the idea that AMPAR content is an important variable in determining the strength of individual synapses.

Taken together with the existing literature, our results indicate that the role of $\alpha 7 \mathrm{nAChR}$ in somatosensory cortex, and perhaps in all cortical areas, is pervasive. Such a role is in keeping with the widespread distribution of cholinergic afferents through the cortex and elsewhere in the brain (Woolf, 1991) and their frequent triadic relationship with glutamatergic terminals and dendritic spines (Aoki and Kabak, 1992). Mice lacking $\alpha 7 \mathrm{nAChR}$ do not display obvious anatomical or behavioral abnormalities (OrrUrtreger et al., 1997; Paylor et al., 1998), so it is likely that $\alpha 7 \mathrm{nAChR}$ is necessary for refining, rather than establishing, sensory receptive field properties and other types of cortical organization dependent on precise synaptic connectivity. The widely known effects of nicotine on cognitive and attentional processes suggest that the role of $\alpha 7 \mathrm{nAChR}$ will emerge as these high-order processes become better understood.

\section{REFERENCES}

Albuquerque EX, Alkondon M, Pereira EF, Castro N, Schrattenholz A, Barbosa C, Bonfante-Cabarcas R, Aracava Y, Eisenberg H, Maelicke A (1997) Properties of neuronal nicotinic acetylcholine receptors: pharmacological characterization and modulation of synaptic function. J Pharmacol Exp Ther 280:1117-1136.

Alkondon M, Pereira EF, Albuquerque EX (1998) Alpha-bungarotoxinand methyllycaconitine-sensitive nicotinic receptors mediate fast synaptic transmission in interneurons of rat hippocampal slices. Brain Res 810:257-263.

Altschuler RA, Wenthold RJ, Schwartz AM, Haser WG, Curthoys NP, Parakkal MH, Fex J (1984) Immunocytochemical localization of glutaminase-like immunoreactivity in the auditory nerve. Brain Res 291:173-178.

Amador M, Dani J (1995) Mechanism for modulation of nicotinic acetylcholine receptors that can influence synaptic transmission. J Neurosci 15:4525-4532.

Aoki C, Kabak S (1992) Cholinergic terminals in the cat visual cortex: ultrastructural basis for interaction with glutamate-immunoreactive neurons and other cells. Vis Neurosci 8:177-191.

Aoki C, Kaneko T, Starr A, Pickel VM (1991) Identification of mitochondrial and non-mitochondrial glutaminase within select neurons and glia of rat forebrain by electron microscopic immunocytochemistry. J Neurosci Res 28:531-548.

Aoki C, Rhee J, Lubin M, Dawson TM (1997) NMDA-R1 subunit of the cerebral cortex co-localizes with neuronal nitric oxide synthase at preand postsynaptic sites and in spines. Brain Res 750:25-40.

Aoki C, Bredt DS, Fenstemaker S, Lubin M (1998) The subcellular distribution of nitric oxide synthase relative to the NR1 subunit of NMDA receptors in the cerebral cortex. Prog Brain Res 118:83-97.

Apel ED, Glass DJ, Moscoso LM, Yancopoulos GD, Sanes JR (1997) Rapsyn is required for MuSK signaling and recruits synaptic components to a MuSK-containing scaffold. Neuron 18:623-635.

Arai Y, Mizuguchi M, Takashima S (1997) Developmental changes of glutamate receptors in the rat cerebral cortex and hippocampus. Anat Embryol (Berl) 195:65-70.

Aramakis VB, Metherate R (1998) Nicotine selectively enhances NMDA receptor-mediated synaptic transmission during postnatal development in sensory neocortex. J Neurosci 18:8485-8495.

Aramakis VB, Hsieh CY, Leslie FM, Metherate R (2000) A critical period for nicotine-induced disruption of synaptic development in rat auditory cortex. J Neurosci 20:6106-6116.

Barrantes GE, Rogers AT, Lindstrom J, Wonnacott S (1995) Alphabungarotoxin binding sites in rat hippocampal and cortical cultures: initial characterisation, colocalisation with alpha 7 subunits and upregulation by chronic nicotine treatment. Brain Res 672:228-236.

Baskerville K, Schweitzer J, Herron P (1997) Effects of cholinergic depletion on experience-dependent plasticity in the cortex of the rat. Neuroscience 80:1159-1169.

Bear MF, Singer W (1986) Modulation of visual cortical plasticity by acetylcholine and noradrenaline. Nature 320:172-176.

Bina KG, Guzman P, Broide RS, Leslie FM, Smith MA, O'Dowd DK (1995) Localization of alpha 7 nicotinic receptor subunit mRNA and alpha-bungarotoxin binding sites in developing mouse somatosensory thalamocortical system. J Comp Neurol 363:321-332.

Brennan EM, Martin LJ, Johnston MV, Blue ME (1997) Ontogeny of non-NMDA glutamate receptors in rat barrel field cortex: II. AlphaAMPA and kainate receptors. J Comp Neurol 386:29-45.

Broide RS, O'Connor LT, Smith MA, Smith JA, Leslie FM (1995) Developmental expression of alpha 7 neuronal nicotinic receptor messenger RNA in rat sensory cortex and thalamus. Neuroscience 67:83-94.

Chu Z, Zhou F, Hablitz J (2000) Nicotinic acetylcholine receptormediated synaptic potentials in rat neocortex. Brain Res 887:399-405.

Contestabile A (2000) Roles of NMDA receptor and nitric oxide production in brain development. Brain Res Rev 32:476-509.

Cudeiro J, Rivadulla C (1999) Sight and insight- on the physiological role of nitric oxide in the visual system. Trends Neurosci 22:109-115.

Dev KK, Nishimune A, Henley JM, Nakanishi S (1999) The protein kinase $\mathrm{C}$ alpha binding protein PICK1 interacts with short but not long 
form alternative splice variants of AMPA receptor subunits. Neuropharmacology 38:635-644

Dominguez del Toro E, Juiz J, Peng X, Lindstrom J, Criado M (1994) Immunocytochemical localization of the alpha 7 subunit of the nicotinic acetylcholine receptor in the rat central nervous system. J Comp Neurol 349:325-342.

Durand GM, Kovalchuk Y, Konnerth A (1996) Long-term potentiation and functional synapse induction in developing hippocampus. Nature 381:71-75

Edwards FA (1995) Anatomy and electrophysiology of fast central synapses lead to a structural model for long-term potentiation. Physiol Rev 75:759-787.

Erisir A, Van Horn SC, Bickford ME, Sherman SM (1997) Immunocytochemistry and distribution of parabrachial terminals in the lateral geniculate nucleus of the cat: a comparison with corticogeniculate terminals. J Comp Neurol 377:535-549.

Fabian-Fine R, Skehel P, Errington ML, Davies HA, Sher E, Stewart MG, Fine A (2001) Ultrastructural distribution of the $\alpha 7$ nicotinic acetylcholine receptor subunit in rat hippocampus. J Neurosci 21:7993-8003

Feldman DE, Nicoll RA, Malenka RC (1999) Synaptic plasticity at thalamocortical synapses in developing rat somatosensory cortex: LTP, LTD, and silent synapses. J Neurobiol 41:92-101.

Feng G, Steinbach JH, Sanes JR (1998) Rapsyn clusters neuronal acetylcholine receptors but is inessential for formation of an interneuronal cholinergic synapse. J Neurosci 18:4166-4176.

Fox K, Schlaggar BL, Glazewski S, O’Leary DD (1996) Glutamate receptor blockade at cortical synapses disrupts development of the thalamocortical and columnar organization in somatosensory cortex. Proc Natl Acad Sci USA 93.5584-5589.

Frazier CJ, Rollins YD, Breese CR, Leonard S, Freedman R, Dunwiddie TV (1998a) Acetylcholine activates an alpha-bungarotoxin-sensitive nicotinic current in rat hippocampal interneurons, but not in pyramidal cells. J Neurosci 18:1187-1195.

Frazier CJ, Buhler AV, Weiner JL, Dunwiddie TV (1998b) Synaptic potentials mediated via alpha-bungarotoxin-sensitive nicotinic acetylcholine receptors in rat hippocampal interneurons. J Neurosci 18:8228-8235.

Fuchs JL (1989) [ ${ }^{125}$ I] alpha-bungarotoxin binding marks primary sensory area developing rat neocortex. Brain Res 501:223-234.

Gil Z, Connors BW, Amitai Y (1997) Differential regulation of neocortical synapses by neuromodulators and activity. Neuron 19:679-686.

Glass DJ, Bowen DC, Stitt TN, Radziejewski C, Bruno J, Ryan TE, Gies DR, Shah S, Mattsson K, Burden SJ, DiStefano PS, Valenzuela DM, DeChiara TM, Yancopoulos GD (1996) Agrin acts via a MuSK receptor complex. Cell 85:513-523.

Gray EG (1959) Axo-somatic and axo-dendritic synapses of the cerebral cortex. J Anat 93:420-433.

Hatton GI, Yang QZ (2002) Synaptic potentials mediated by $\alpha 7$ nicotinic acetylcholine receptors in supraoptic nucleus. J Neurosci 22:29-37.

Hefft S, Hulo S, Bertrand D, Muller D (1999) Synaptic transmission at nicotinic acetylcholine receptors in rat hippocampal organotypic cultures and slices. J Physiol (Lond) 515:769-776.

Herrmann K (1996) Differential distribution of AMPA receptors and glutamate during pre- and postnatal development in the visual cortex of ferrets. J Comp Neurol 375:1-17.

Huh K, Fuhrer C (2001) Isolation of PICK1 as a binding substrate for alpha 7 nicotinic receptors. Soc Neurosci Abstr 31:145.7.

Isaac JT, Nicoll RA, Malenka RC (1995) Evidence for silent synapses: implications for the expression of LTP. Neuron 15:427-434

Isaac JT, Crair MC, Nicoll RA, Malenka RC (1997) Silent synapses during development of thalamocortical inputs. Neuron 18:269-280.

Jacob M, Berg D (1983) The ultrastructural localization of $\alpha$-bungarotoxin binding sites in relation to synapses on chick ciliary ganglion neurons. J Neurosci 3:260-271.

Jones S, Sudweeks S, Yakel JL (1999) Nicotinic receptors in the brain: correlating physiology with function. Trends Neurosci 22:555-561.

Kharazia VN, Weinberg RJ (1999) Immunogold localization of AMPA and NMDA receptors in somatic sensory cortex of albino rat. J Comp Neurol 412:292-302.

Kharazia VN, Wenthold RJ, Weinberg RJ (1996) GluR1-immunopositive interneurons in rat neocortex. J Comp Neurol 368:399-412.

Kilgard M, Merzenich M (1998) Cortical map reorganization enabled by nucleus basalis activity. Science 279:1714-1718.

Kleinschmidt A, Bear MF, Singer W (1987) Blockade of NMDA receptors disrupts experience-dependent plasticity of kitten striate cortex. Science 238:355-358.

Liao D, Hessler NA, Malinow R (1995) Activation of postsynaptically silent synapses during pairing-induced LTP in CA1 region of hippocampal slice. Nature 375:400-404.

Liao D, Zhang X, O'Brien R, Ehlers MD, Huganir RL (1999) Regulation of morphological postsynaptic silent synapses in developing hippocampal neurons. Nat Neurosci 2:37-43.

Ling EA, Leblond CP (1973) Investigation of glial cells in semithin sections. II. Variation with age in the numbers of the various glial cell types in rat cortex and corpus callosum. J Comp Neurol 149:73-81.

Lubin M, Erisir A, Aoki C (1999) Ultrastructural localization of the alpha $7 \mathrm{nAChR}$ subunit in guinea pig medial prefrontal cortex. Ann NY Acad Sci 868:628-632.

McGehee DS (1999) Molecular diversity of neuronal nicotinic acetylcholine receptors. Ann NY Acad Sci 868:565-577.

McGehee DS, Heath MJ, Gelber S, Devay P, Role LW (1995) Nicotine enhancement of fast excitatory synaptic transmission in CNS by presynaptic receptors. Science 269:1692-1696.

McLane KE, Wu X, Lindstrom JM, Conti-Tronconi BM (1992) Epitope mapping of polyclonal and monoclonal antibodies against two alphabungarotoxin-binding alpha subunits from neuronal nicotinic receptors. J Neuroimmunol 38:115-128.

McMahan UJ (1990) The agrin hypothesis. Cold Spring Harb Symp Quant Biol 55:407-418.

Müller CM, Singer W (1989) Acetylcholine-induced inhibition in the cat visual cortex is mediated by a GABAergic mechanism. Brain Res 487:335-342.

Nusser Z, Lujan R, Laube G, Roberts JD, Molnar E, Somogyi P (1998) Cell type and pathway dependence of synaptic AMPA receptor number and variability in the hippocampus. Neuron 21:545-559.

Orr-Urtreger A, Goldner F, Saeki M, Lorenzo I, Goldberg L, De Biasi M, Dani JA, Patrick JW, Beaudet AL (1997) Mice deficient in the $\alpha 7$ neuronal nicotinic receptor lack $\alpha$-bungarotoxin binding sites and hippocampal fast nicotinic currents. J Neurosci 17:9165-9171.

Parnavelas JG, Luder R, Pollard SG, Sullivan K, Lieberman AR (1983) A qualitative and quantitative ultrastructural study of glial cells in the developing visual cortex of the rat. Philos Trans R Soc Lond B Biol Sci 301:55-84.

Paxinos G, Watson C (1998) The rat brain in stereotaxic coordinates. New York: Academic.

Paylor R, Nguyen M, Crawley J, Patrick J, Beaudet A, Orr-Urtreger A (1998) Alpha7 nicotinic receptor subunits are not necessary for hippocampal-dependent learning or sensorimotor gating: a behavioral characterization of Acra7-deficient mice. Learn Mem 5:302-316.

Peters A, Palay SL, Webster H (1991) The fine structure of the nervous system. New York: Oxford.

Petralia RS, Wenthold RJ (1992) Light and electron immunocytochemical localization of AMPA-selective glutamate receptors in the rat brain. J Comp Neurol 318:329-354.

Petralia RS, Wang YX, Mayat E, Wenthold RJ (1997) Glutamate receptor subunit 2-selective antibody shows a differential distribution of calcium-impermeable AMPA receptors among populations of neurons. J Comp Neurol 385:456-476.

Petralia RS, Esteban JA, Wang YX, Partridge JG, Zhao HM, Wenthold RJ, Malinow R (1999) Selective acquisition of AMPA receptors over postnatal development suggests a molecular basis for silent synapses. Nat Neurosci 2:31-36.

Phend KD, Weinberg RJ, Rustioni A (1992) Techniques to optimize post-embedding single and double staining for amino acid neurotransmitters. J Histochem Cytochem 40:1011-1020.

Racca C, Stephenson FA, Streit P, Roberts JD, Somogyi P (2000) NMDA receptor content of synapses in stratum radiatum of the hippocampal CA1 area. J Neurosci 20:2512-2522.

Rasmusson D (2000) The role of acetylcholine in cortical synaptic plasticity. Behav Brain Res 115:205-218.

Roerig B, Nelson DA, Katz LC (1997) Fast synaptic signaling by nicotinic acetylcholine and serotonin $5-\mathrm{HT}_{3}$ receptors in developing visual cortex. J Neurosci 17:8353-8362.

Role LW, Berg DK (1996) Nicotinic receptors in the development and modulation of CNS synapses. Neuron 16:1077-1085.

Rumpel S, Hatt H, Gottmann K (1998) Silent synapses in the developing rat visual cortex: evidence for postsynaptic expression of synaptic plasticity. J Neurosci 18:8863-8874.

Sanes JR, Lichtman JW (1999) Development of the vertebrate neuromuscular junction. Annu Rev Neurosci 22:389-442.

Schoepfer R, Conroy WG, Whiting P, Gore M, Lindstrom J (1990) Brain alpha-bungarotoxin binding protein cDNAs and mAbs reveal subtypes of this branch of the ligand-gated ion channel gene superfamily. Neuron 5:35-48.

Serpinskaya AS, Feng G, Sanes JR, Craig AM (1999) Synapse formation by hippocampal neurons from agrin-deficient mice. Dev Biol 205:65-78

Shi SH, Hayashi Y, Petralia RS, Zaman SH, Wenthold RJ, Svoboda K, Malinow R (1999) Rapid spine delivery and redistribution of AMPA receptors after synaptic NMDA receptor activation. Science 284:1811-1816.

Sillito A, Kemp J (1983) Cholinergic modulation of the functional organization of the cat visual cortex. Brain Res 289:143-155.

Sillito AM, Murphy CL (1987) The cholinergic modulation of cortical function. In: Cerebral cortex, Vol 6 (Jones EG, Peters A, eds), pp 161-185. New York: Plenum.

Somogyi P, Halasy K, Somogyi J, Storm-Mathisen J, Ottersen OP (1986) Quantification of immunogold labeling reveals enrichment of glutamate 
in mossy and parallel fibre terminals in cat cerebellum. Neuroscience 19:1045-1050.

Takumi Y, Ramirez-Leon V, Laake P, Rinvik E, Ottersen OP (1999) Different modes of expression of AMPA and NMDA receptors in hippocampal synapses. Nat Neurosci 2:618-624.

Vernino S, Amador M, Luetje C, Patrick J, Dani J (1992) Calcium modulation and high calcium permeability of neuronal nicotinic acetylcholine receptors. Neuron 8:127-134.

Woolf N (1991) Cholinergic systems in mammalian brain and spinal cord. Prog Neurobiol 37:475-524.

Wouterlood FG, Jorritsma-Byham B (1993) The anterograde neuroanatomical tracer biotinylated dextran-amine: comparison with the tracer
Phaseolus vulgaris-leucoagglutinin in preparations for electron microscopy. J Neurosci Methods 48:75-87.

Wu G, Malinow R, Cline HT (1996) Maturation of a central glutamatergic synapse. Science 274:972-976.

Xia J, Zhang X, Staudinger J, Huganir RL (1999) Clustering of AMPA receptors by the synaptic PDZ domain-containing protein PICK1. Neuron $22: 179-187$.

Xiang A, Huguenard JR, Prince DA (1998) Cholinergic switching within neocortical inhibitory networks. Science 281:985-988.

Zhang Z-W, Vijayaraghavan S, Berg DK (1994) Neuronal acetylcholine receptors that bind $\alpha$-bungarotoxin with high affinity function as ligandgated ion channels. Neuron 12:167-177. 